\title{
6 Inoffizielle Narrative zur Kampagne gegen Rechtsabweichler (ohne Duldung) oder „Untergrund“-Geschichtsschreibung
}

Aufgrund der Tatsache, dass Publikationen in China durch die entsprechenden Behörden überprüft und genehmigt werden müssen, um auf legalem Wege vertrieben werden zu können, ist durch die im Zuge dessen durchgeführte Zensur ganz automatisch auch ein Bereich von Narrativen entstanden, den man als „Untergrund“-Geschichtsschreibung bezeichnen kann. In diesen Bereich fällt all das, was inhaltlich eben nicht den Anforderungen der staatlichen Behörden entspricht, aber dennoch auf ,illegalem“ Wege nach China vordringen konnte. In der Praxis bedeutet Zensur nämlich häufig nicht, dass die alternativen Darstellungen der Vergangenheit gar nicht mehr veröffentlicht werden, sondern dass die Inhalte des hier gewählten Untersuchungsgegenstands der Kampagne gegen Rechtsabweichler in anderen, nicht durch die Partei legitimierten Formen veröffentlicht werden - entweder im Ausland und/oder auf dem chinesischen Schwarzmarkt oder zum Beispiel über das Internet über Mailinglisten.

Der Untersuchungsgegenstand dieser Kategorie meint also eine Form des Umgangs mit der Vergangenheit, die nicht mehr in den von der Partei geduldeten bzw. tolerierten Bereich fällt und deren Akteure jenseits der von der KPCh vorgegebenen Grenzen des in der VR China Sagbaren agieren. Diese Form der Geschichtsschreibung bzw. des öffentlichen Erinnerns stellt in der Regel nicht nur einen Gegensatz zu dem zum staatlichen Kanon gewordenen Konsens der Resolution von 1981 dar, sondern kann im Zuge dessen auch eine Herausforderung der Herrschaftslegitimation der Partei bedeuten.

Die Akteure der hier dargelegten Kategorie unterscheiden sich dabei auf den ersten Blick kaum von jenen, die innerhalb der staatlichen Toleranzgrenze agieren. Auch hier gilt, dass Zeitzeugen bzw. Opfer und ihre Angehörigen vor allem seit den 1990er Jahren ihre Erinnerungen an die Ereignisse in Form von Memoiren oder Kurzmemoiren, als Monografien oder auch in Geschichtszeitungen veröffentlichen. Teilweise beteiligen sich auch ehemals hochrangige Parteikader an dieser Form der Neudeutung der Kampagne gegen Rechtsabweichler. Jedoch nehmen auch chinesische Dissidenten eine wichtige Rolle im Kampf gegen das staatlich verordnete Vergessen der „historischen Fehler“ der Partei ein, welchen sie meist mit für die Partei inakzeptablen politischen Forderungen wie etwa der nach der Durchsetzung von Menschenrechten in China verknüpfen. Einige dieser Akteure haben nach dem Ende der Kulturrevolution die VR China verlassen und agieren aus dem westlichen Ausland, Taiwan oder Hongkong. 
Die kritischen Betrachtungen der Vergangenheit basieren also auch hier meist auf persönlichen Erinnerungen bzw. sind durch sie geprägt. Teilweise werden sie, mangels Zugangs zu entsprechenden Archivmaterialien, auch durch die sogenannte „graue Literatur“ geprägt, das heißt durch Privatdrucke, die nicht im Buchhandel erhältlich sind. Die Intentionen der Autoren umfassen neben dem Schaffen von alternativen Erinnerungsorten für verstorbene ehemalige Rechtsabweichler häufig auch die Aufarbeitung des eigenen durchlebten Traumas. Insbesondere aber fallen die im Folgenden untersuchten Quellen dadurch auf, dass sie vor allem dem Ziel dienen, die „wahre“ Geschichte der Ereignisse jener Jahre weiterzugeben, um so einen Beitrag zu einem gesellschaftlichen Fortschritt $\mathrm{zu}$ leisten.

Einen möglichen Erklärungsansatz, warum eine solche Form von „Wahrheit“ für Regime wie das der VR China vor allem auch zu einem unbequemen politischen Faktor werden kann, liefert Hannah Arendt bereits 1961 in ihrem Werk Zwischen Vergangenheit und Zukunft. Übungen im politischen Denken:

\footnotetext{
Wahrhaftigkeit ist nie zu den politischen Tugenden gerechnet worden, weil sie in der Tat wenig zu dem eigentlich politischen Geschäft, der Veränderung der Welt und der Umstände, unter denen wir leben, beizutragen hat. Dies wird erst anders, wenn ein Gemeinwesen im Prinzip sich der Lüge als einer politischen Waffe bedient, wie es etwa im Falle der totalen Herrschaft der Fall ist; dann allerdings kann Wahrhaftigkeit als solche, auch wenn sie von keinerlei Gruppen- oder Machtinteressen unterstützt wird, zu einem politischen Faktor ersten Ranges werden. Wo prinzipiell und nicht nur gelegentlich gelogen wird, hat derjenige, der einfach sagt, was ist, bereits zu handeln angefangen, auch wenn er dies gar nicht beabsichtigte. In einer Welt, in der man mit Tatsachen nach Belieben umspringt, ist die einfachste Tatsachenfeststellung bereits eine Gefährdung der Machthaber. ${ }^{523}$
}

Diese „einfache Tatsachenfeststellung“ als politische Waffe kann im Falle der Kampagne gegen Rechtsabweichler etwa die menschenunwürdige Behandlung der Opfer im Laogai-System sein, was wiederum auch einen Diskurs um Menschenrechtsverletzungen im gegenwärtigen China nach sich ziehen kann, da das System der Zwangsarbeit ja auch im gegenwärtigen China faktisch noch immer existiert. Dies könnte zum Beispiel aber auch der immer wieder formulierte Vorwurf des Verfassungsbruchs durch die KPCh während der Kampagne gegen Rechtsabweichler sein.

Auch wenn die Darstellung der Ereignisse der Kampagne gegen Rechtsabweichler in dieser Kategorie nicht zwingend immer nur auf „Wahrheit“, sondern in vielen Fällen auf „Wahrnehmung“ beruht, ist diese Mischung aus Wahrheit und Wahrnehmung zu einem politisch unerwünschten Akt geworden. Wie bereits im

523 Arendt 1994, S. 354. 
Theorieteil dieser Arbeit dargelegt, muss dabei berücksichtigt werden, dass die auf persönlichen Erinnerungen beruhende Darstellung der Vergangenheit ein Problem für die wissenschaftliche Betrachtung darstellen kann, da sich die tatsächliche Wahrheit nur sehr schwer aus der Wahrnehmung der Einzelnen extrahieren lässt. Wenn die Konstruktion der „Wahrheit“ auf persönlichen Erinnerungen beruht, muss man zudem stets die Möglichkeit in Betracht ziehen, dass das „Sagen, was war“, auch mit einer unbewussten oder manchmal sogar bewussten Verbreitung von Unwahrheiten bzw. Verzerrungen der Tatsachen einhergeht.

\section{Wie chinesische Intellektuelle der Zensur trotzen}

Aufgrund der Nachwirkungen der Studierendenproteste des Jahres 1989 und des daraus resultierenden Kampfes der Partei um die Aufrechterhaltung ihrer Herrschaftslegitimation einerseits sowie einer wahren Flut an Veröffentlichungen von Biografien über (ehemalige) politische Führer Chinas, die eine aus Sicht der Partei unerwünschte Perspektive auf die eigene Geschichte warfen, andererseits, verabschiedete das Staatliche Hauptamt für Presse- und Verlagswesen im Jahr 1993 neue Regularien zur Veröffentlichung inoffizieller Narrative. Demnach sollte nichts mehr veröffentlicht werden dürfen, was die historischen Fakten verzerrte. ${ }^{524}$ Somit stellen die in diesem Kapitel besprochenen, unerwünschten Narrative zur Geschichte der Partei bzw. der Kampagne gegen Rechtsabweichler aus der offiziellen Sicht der KPCh also ein verzerrtes Bild der Geschichte dar. Dies hatte eben jenen bereits beschriebenen Effekt, der nicht etwa dazu führte, dass die Anzahl der „unerwünschten“ Publikationen abnahm, sondern nur dazu, dass diese Art von Narrativen auf von der Partei nicht legitimiertem Wege nach China vordrang. Was nun als „unerwünscht“ und was hingegen als ,toleriert“ eingestuft werden würde, lässt sich anhand dieser Regularien jedoch inhaltlich nicht genau voneinander abgrenzen, da diese sehr schwammig formuliert sind und keine klaren Kriterien vorgeben.

Wie im Folgenden dargelegt, können die Gründe dafür, dass die in den alternativen Darstellungen der Vergangenheit geschaffenen Narrative nicht innerhalb der Toleranzgrenze der Partei fallen, sehr vielfältig sein - die Gründe für eine Zensur in China können dabei sowohl inhalts- als auch personenbedingt sein. Zu berücksichtigen gilt allerdings auch die jeweilige politische Situation der Veröffentlichungszeit, beispielweise waren in der ersten Hälfte der 1990er Jahre die Vorgaben der Behörde besonders streng, ebenso, wie es seit der Amtsübernahme

524 Barmé 1996, S. 30. 
Xi Jinpings zu beobachten ist. Das heißt, einige der in diese Kategorie fallenden Narrative sind nicht ausschließlich aufgrund ihres Inhalts zensiert worden, sondern möglicherweise vielmehr den politischen Umständen der Zeit zum Opfer gefallen.

In Bezug auf die alternativen Narrative zur Kampagne gegen Rechtsabweichler war eines der prominentesten Opfer der Zensur im Jahr 1993 der Film Der Blaue Drache (Lan fengzheng 蓝风筝) des Regisseurs Tian Zhuangzhuang 田壮壮, eines der bekanntesten Vertreter der Fünften Generation der chinesischen Filmschaffenden. ${ }^{525}$ Der Film wurde von einer Hongkonger Produktionsfirma finanziert, ohne Genehmigung der chinesischen Behörden gedreht und schließlich außer Landes geschmuggelt, um beim Tokyo International Film Festival uraufgeführt zu werden. Der Film setzt sich kritisch mit der Rolle der Autoritäten während der politischen Kampagnen im China der 1950er und 1960er Jahre auseinander und umfasst eben auch eine Kritik an der Kampagne gegen Rechtsabweichler. Eine solche Darstellung der durch die KPCh begangenen Fehler der Vergangenheit kam für die Partei so kurz nach den Studierendenprotesten des Jahres 1989 zum falschen Zeitpunkt, wollte sie einen öffentlichen Diskurs um ihre Vergehen doch um jeden Preis vermeiden. Der Regisseur selbst wurde aufgrund seiner durch den Film vermittelten Kritik an der Partei mit einem zehnjährigen Drehverbot in China bestraft, jedoch wurde er bereits Ende der 1990er Jahre langsam wieder in die chinesische Filmindustrie reintegriert. Trotz der bis heute bestehenden staatlichen Verbannung des Films, konnte er durch den Verkauf von Raubkopien über den Schwarzmarkt in hoher Anzahl nach China vordringen und wurde im Laufe der Jahre zu einem der bekanntesten Filme dieser Generation Filmschaffender in China. ${ }^{526}$

Rund ein Jahr später kam mit Ich war Maos Leibarzt zum Leidwesen der Partei durch den ehemaligen Leibarzt Maos Li Zhisui ein Buch in Umlauf, welches die $\mathrm{KPCh}$, insbesondere jedoch die Ikone Mao Zedong, in einem mehr als ungünstigen Licht erscheinen ließ. Dieses Buch fand insbesondere im Ausland Beachtung, doch auch in China wurde es trotz der Zensur durch die Behörden ein durchschlagender Erfolg. ${ }^{527}$ Darüber hinaus konnten andere dieser in China zensierten alternativen Betrachtungen der Vergangenheit in den folgenden Jahren auch im Ausland hohe Verkaufszahlen erzielen und somit das Bild Chinas im Westen prägen. $\mathrm{Zu}$ ihnen zählt auch die in den westlichen Medien sehr positiv besprochene, jedoch unter Chinawissenschaftlern sehr kritisch diskutierte Mao-Bio-

525 In China wird die eigene Filmgeschichte nach Generationen periodisiert. Siehe Kramer 1997. 526 Pickowicz 1995, S. 219.

527 Eine umfassende Analyse der Darstellung der Kampagne gegen Rechtsabweichler Li Zhisuis erfolgt in Kapitel 7.1.1. 
grafie Mao: Das Leben eines Mannes, das Schicksal eines Volkes von Jung Chang (eigentlich Zhang Rong 张戎) und ihrem Ehemann Jon Halliday aus dem Jahr 2005. In dieser porträtieren die Autoren den Vorsitzenden tendenziös als blutrünstiges Monster, das für den Tod von rund 70 Millionen Menschen verantwortlich gewesen sei. Im Jahr 2006 wurde von einem Hongkonger Verlag schließlich auch eine chinesische Version des Buches herausgegeben (Mao Zedong: Xian wie renshi de gushi 毛澤東 : 鮮為人知的故事; wörtl.: Mao Zedong: Eine wenig bekannte Geschichte), welche ebenfalls auf „illegalen“ Wegen nach China vordringen konnte. ${ }^{528}$

Einige Autoren, die mit ihren Werken zuvor noch innerhalb des staatlichen Toleranzbereiches agierten und diese somit auf legalem Wege in China veröffentlichten, konnten mit ihren Nachfolgewerken plötzlich auch zu Akteuren der, aus Sicht der KPCh, unerwünschten Geschichtsschreibung werden. Hu Pings im Jahr 2016 erschienenes Buch Warum konnte Mao Zedong die Kulturrevolution ins Leben rufen? (Mao Zedong weishenme hui fadong Wenhua dageming? 毛澤東為 什麼會發動文化大革命?) konnte eben nicht in der VR China, sondern nur in Taiwan veröffentlicht werden, obwohl die darin enthaltene wissenschaftliche Auseinandersetzung über die Gründe der Kulturrevolution nicht deutlich kritischer ausfiel als die Auseinandersetzung mit der Kampagne gegen Rechtsabweichler in seinem zuvor diskutierten Werk Internes 1957: Altar des Leidens. ${ }^{529}$ Die Gründe dafür können einerseits mit der restriktiveren Geschichtspolitik der VR China seit dem Amtsantritt Xi Jinpings zusammenhängen, andererseits aber auch damit, dass Hu Ping sich in den Jahren unmittelbar vor der Veröffentlichung des Buches zunehmend kritisch öffentlich über die aktuelle Regierung und die Einschränkungen der Redefreiheit in China geäußert hat. Dies wird zum Beispiel anhand eines Interviews deutlich, welches 2016 auf der Internetseite der TuidangBewegung (Tuidang yundong 退党运动) ${ }^{530}$ veröffentlicht wurde und in dem er seine Kritik an den Zensurmaßnahmen und der jüngeren Entwicklungen innerhalb der VR China darlegt:

Since taking power, Xi Jinping has taken systematic steps to shut down the space for expression for Chinese liberal-leaning intellectuals, which had been constrained to begin

528 Für eine kritische, wissenschaftliche Auseinandersetzung mit Mao: Das Leben eines Mannes, Schicksal eines Volkes siehe Gao 2008, S. $65 \mathrm{ff}$.

$529 \mathrm{Hu} 2016$.

530 Die Tuidang-Bewegung wurde im Jahr 2004 als Teil des Widerstandes der Falun-GongPraktizierenden gegründet. Nach und nach wurde daraus eine größere Dissidenten-Bewegung, die sich der Förderung eines alternativen politischen Systems in China verschrieben hat. Siehe Tuidang Movement, https://en.tuidang.org/contact-us. 
with. Even the Gongshi (Consensus) website and the Yanhuang Chunqiu magazine have been shut down and are no longer tolerated - and you can well imagine the terrorizing effect this has. I believe that the international community, including the United States and other Western countries, is seeing more and more clearly that the Chinese regime has had no intention of carrying out political and democratic reforms. On the contrary, as the Chinese economy grows bigger and bigger, the regime has become more confident and armed with more resources. These are obvious developments, and even some of the China apologists in the West are seeing that things are not panning out as they expected. ${ }^{531}$

Neben wissenschaftlichen Texten, Filmen, Memoiren oder Biografien stellten auch vorwiegend über das Internet verbreitete inoffizielle respektive unabhängige Geschichtszeitungen ohne Publikationslizenz ein wichtiges Medium für ehemalige Rechtsabweichler oder ihrer Angehörigen dar, ihre persönlichen Erlebnisse während und nach der Kampagne gegen Rechtsabweichler aufzuarbeiten und von der offiziellen Geschichtsschreibung abweichende Versionen der Vergangenheit zu zirkulieren. Einen kritischen Blick auf die Geschichte der Mao-Ära werfen zum Beispiel die Autoren der im Jahr 2008 durch den Filmhistoriker Wu Di 吴迪 gegründeten Zeitschrift Jiyi 记忆 (wörtl.: Erinnerung oder Gedächtnis). ${ }^{532}$ Eine explizite Auseinandersetzung mit der Kampagne gegen Rechtsabweichler stellen zum Beispiel die Beiträge der im Jahr 2010 gegründeten Geschichtszeitung Bashan Yeyu dar, deren Neudeutung der Geschichte nachfolgend einer genauen Analyse unterzogen wird. Das Problem an solchen Zeitschriften für die KPCh ist, dass ihr Einfluss auf sie recht begrenzt ist. Die Partei kann zwar veranlassen, dass entsprechende Webseiten gesperrt werden, jedoch können sie die Verbreitung nicht ganz verhindern, denn teilweise werden sie über E-Mail-Listen zirkuliert. Somit sind auch diese ein wichtiger Bestandteil im Kampf um das kollektive Gedächtnis.

Einige der Akteure der alternativen Geschichtsschreibung widersetzten sich im Laufe der Jahre immer wieder öffentlich der Zensur und setzten sich damit gewissermaßen dafür ein, dass die in diesem Kapitel besprochenen Narrative zur Kampagne gegen Rechtsabweichler eines Tages auch innerhalb Chinas veröffentlicht werden können und damit innerhalb der Grenze des Sagbaren Platz finden. Im Jahr 2010 forderte zum Beispiel der bereits in Kapitel 5 angesprochene Li Rui gemeinsam mit einer Reihe anderer öffentlicher Intellektueller und ehemals hochrangiger Parteikader, wie etwa Zhong Peizhang 钟沛璋, einst Propagandachef im Politbüro der KPCh, in einer Petition an den Ständigen Ausschuss des Nationalen Volkskongresses ein Ende der staatlichen Zensur. Die Petition

531 Tuidang Movement 2016, https://en.tuidang.org/human-rights-2/2016/11/for-over-36-yearsgrassroots-elections-in-china-have-made-no-progress-an-interview-with-hu-ping.html.

532 Siehe Béja 2019, S. $34 \mathrm{f}$. 
verwies dabei auch auf den Verstoß der Regierung gegen Artikel 35 der Verfassung der VR China, der die Redefreiheit garantiert. Diese Petition wurde von 500 Unterstützern unterzeichnet - bemerkenswert daran ist, dass rund 90 Prozent von ihnen Parteimitglieder gewesen sind. Dies unterstreicht erneut die Uneinigkeit der Partei im Umgang mit der staatlichen Zensur, was wiederum ein Erklärungsansatz für die teilweise sehr unterschiedlichen Entscheidungsprozesse hinsichtlich der Genehmigung von Veröffentlichungen über die offizielle Geschichtsschreibung hinausgehender Narrative bzw. deren Zensur sein kann. Eine Berichterstattung über den Brief in den Medien wurde durch die Partei unterbunden. ${ }^{533}$ Dies zeigt, dass teilweise auch Akteure der staatlich tolerierten inoffiziellen Geschichtsschreibung in einer für die Partei nicht akzeptablen Weise öffentlich jenseits der staatlichen Toleranzgrenze agieren.

Auch die Aufarbeitung der Geschichte der Kampagne gegen Rechtsabweichler geht innerhalb dieser Kategorie häufig direkt mit politischen Forderungen an die Partei einher. Diese können sowohl die Forderung nach einer offiziellen Aufarbeitung der Geschichte als auch die nach einer öffentlichen Entschuldigung der Partei an die Opfer umfassen. Meist sind diese auch verbunden mit Forderungen nach einer angemessenen Entschädigung der Opfer - dies zeigt erneut, welch weitreichende Folgen die politischen Entscheidungen nach 1976 rund um die Einzelfallkorrekturen der Rechtsabweichler und deren Ungleichbehandlung auch noch in den 2010er Jahren für den öffentlichen Diskurs um die Geschichte hat. Stimmen wie diese werden insbesondere rund um die runden Jahrestage des Beginns der Kampagne laut, wie zum Beispiel im Jahr 2007, als anlässlich des 50. Jahrestags des Beginns des Kampfes gegen die Rechten 55 ehemalige Rechtsabweichler die chinesische Regierung in einem offenen Brief dazu aufriefen, den Opfern bzw. ihren Angehörigen endlich eine angemessene Entschädigung für das durch diesen „historischen Fehler“ ausgelöste Leid zukommen zu lassen. Außerdem forderten sie eine öffentliche Entschuldigung und eine Revidierung der offiziellen Einschätzung der historischen Ereignisse der 1981er Resolution. ${ }^{534}$ Auch rund um den 60. Jahrestag des Beginns der Kampagne im Jahr 2017 gab es eine Reihe von ähnlichen öffentlichen Äußerungen und Forderungen. Zum Beispiel postulierte der chinesische Schriftsteller und Dissident Tan Zuoren 谭作人 die Durchsetzung des Rechts der Angehörigen der ehemaligen Rechtsabweichler auf eine angemessene finanzielle Kompensation in Form eines öf-

533 Feng 2012, S. 136.

534 Bai 2007, https://www.rfa.org/english/china/china_antirightist-20070619.html. 
fentlichen Briefes an die Regierung, der von rund 100 Unterstützern unterzeichnet worden war. ${ }^{535}$

\section{Die Rolle der Dissidenten}

Die Verknüpfung der kritischen Bewertung der Vergangenheit mit politischen Forderungen durch Dissidenten nimmt innerhalb dieser Kategorie der Geschichtsschreibung respektive des Erinnerns einen besonders wichtigen Stellenwert im Kampf um das kollektive Gedächtnis ein. Diese kann aus Sicht der KPCh problematisch sein, weil sie nicht selten mit einer scharfen Kritik an der Politik der VR China nach 1976 bzw. mit der Gegenwart verknüpft ist. Eine Reihe dieser Akteure agieren aus persönlichen negativen Erfahrungen heraus, die sie mit den „historischen Fehlern“ der Partei gemacht haben, und sind somit gleichzeitig auch Zeitzeugen jener Ereignisse. In Bezug auf die Kampagne gegen Rechtsabweichler trifft dies in besonderem Maße auf den im Jahr 1957 als Rechtsabweichler verurteilten Harry Wu zu, der aufgrund dessen mehr als 20 Jahre im Laogai-System zubrachte. Nach seiner Entlassung verließ er China in Richtung USA, wo er sich ab den 1990er Jahren bemühte, auf die Schrecken der Vergangenheit Chinas und das Zwangsarbeitslagersystem, welches auch Jahrzehnte nach dem Tode Maos noch existiert, aufmerksam zu machen und die Menschenrechtsverletzungen öffentlich anzuprangern. Neben der Veröffentlichung seiner in China zensierten Memoiren Nur der Wind ist frei. Meine Jahre in Chinas GULAG (1994) oder Donner der Nacht: Mein Leben in chinesischen Straflagern (2009) führte er seinen Kampf gegen das Vergessen vor allem mit der Gründung der Laogai Research Foundation im Jahr 1992 sowie mit der Eröffnung eines Laogai-Museums in Washington, D.C., im Jahr 2008. Die Mission der Forschungsstiftung ist es neben der Aufklärung der Verbrechen durch die KPCh in der Vergangenheit, einen Beitrag dazu zu leisten, dass das System der Zwangsarbeit eines Tages in China abgeschafft und den damit verbundenen Menschenrechtsverletzungen ein Ende gesetzt wird. ${ }^{536}$ Kurz nach dem plötzlichen Tod Harry Wus im April 2016 wurden die Stiftung und das Museum zunächst geschlossen. Die Stiftung nahm ihre Arbeit im Jahr 2018 jedoch wieder auf und wird seitdem von Xia Ming, Professor für Politikwissenschaften an der City University of New York, als Direktor sowie Chen Kuide, Leiter einer China-Forschungseinrichtung der Universität Princeton, und dem Chinahistoriker Song Yongyi geleitet. Song Yongyi ist Herausgeber einer im Jahr 2002 in Hongkong erschienenen, sehr umfangreichen Datenbank mit Ar-

535 Xin und Qiao 2017.

536 Laogai Research Foundation 2016, https://laogairesearch.org/about-us/. 
chivmaterial zur Kulturrevolution und somit ebenfalls Akteur einer alternativen Geschichtsschreibung zur Geschichte der KPCh. Die Stiftung verkündete im Dezember 2018, dass sie an einer Wiedereröffnung des Museums sowie einer ergänzenden digitalen Ausstellung arbeite, um ihre Mission wieder einer breiten Öffentlichkeit zugänglich zu machen. ${ }^{537}$ Die Tatsache, dass sowohl die Stiftung als auch das Museum nach dem Tode Harry Wus zunächst geschlossen wurden, zeigt, dass die Erinnerungsarbeit zu bestimmten historischen Ereignissen Gefahr läuft, auch mit dem Tod der Zeitzeugen zu sterben.

Bis zu seiner Schließung ergänzte das Museum die Arbeit der Stiftung durch eine visuelle Darstellung der Geschichte des Laogai-Systems von seiner Gründung in den 1950er Jahren bis in die 2010er Jahre. Darüber hinaus fungierte es als eine Art alternativer Erinnerungsort für berühmte Opfer der KPCh bzw. ihrer „historischen Fehler“ wie der Kampagne gegen Rechtsabweichler oder der Kulturrevolution. Am Anfang der Ausstellung wurde auf einer Informationstafel, wie in der gesamten Ausstellung sowohl in chinesischer als auch in englischer Sprache, zunächst erläutert, dass das Laogai-System seit den 1950er Jahren die Funktion ausübe, das Machtmonopol der KPCh aufrechtzuerhalten, indem es für die Beseitigung politischer Gegner eingesetzt werde. Offiziell deklariere die Partei demnach das System der Zwangsarbeit als Schutz des Sozialismus. Im Anschluss daran widmete sich die Ausstellung den schlechten Haftbedingungen in den Arbeitslagern der 1950er und 1960er Jahre. Ausgestellt wurden die sehr einfache Häftlingskleidung sowie eine sehr dünne Decke, die den Insassen auch im tiefsten Winter ausreichen sollte. Darüber hinaus stellten ein sogenannter gepolsterter „Hundehut“ (goutoumao 狗头帽), der den Häftlingen demnach bei Fehlverhalten aufgesetzt wurde und auf den sie dann Schläge mit einem Knüppel erhielten, sowie eine nur 3 mal 3 mal 6 Meter große, komplett abgedunkelte Zelle zur Isolationshaft weitere Exponate dar, die während der Haft Harry Wus zur Bestrafung eingesetzt worden seien. Hier bezog sich die Ausstellung direkt auf die persönlichen Erinnerungen Harry Wus an seine Zeit im Laogai-System, da er diese Form der Bestrafung laut des Ausstellungstextes selbst erlebt habe.

Im Anschluss daran widmete sich die Ausstellung den historischen Hintergründen des Laogai-Systems und ging auch auf bestimmte „historische Fehler“ wie die Kampagne gegen Rechtsabweichler, den Großen Sprung nach vorn und die Kulturrevolution ein. Die Darstellung der Kampagne gegen Rechtsabweichler wurde dabei als eines von vielen Beispielen für Menschenrechtsverletzungen unter der Herrschaft der KPCh angeführt und nicht in besonderer Weise hervor-

537 Yang 2018, https://laogairesearch.org/the-reopening-of-the-laogai-museum-and-the-formati on-of-a-new-board-of-directors/. 
gehoben. Die Ausstellungstafel hierzu besagte, dass die Intellektuellen während der Hundert-Blumen-Bewegung hinterrücks in eine Falle gelockt worden seien. Gezeigt wurden zudem Fotos von öffentlichen Kritiksitzungen und Schmähungen gegen Rechtsabweichler während der Jahre 1957 und 1958 sowie von Exekutionen. Auf eine Nennung der Opferzahlen des Kampfes gegen die Rechten wurde verzichtet, jedoch besagte die Ausstellung, dass seit der Gründung der VR China im Jahr 1949 insgesamt zwischen 40 und 50 Millionen Menschen im Laogai-System ihre Freiheit verloren hätten und es unter der Herrschaft der KPCh rund 65 Millionen unnatürliche Todesfälle gegeben habe. Darüber hinaus stellten die Kuratoren an dieser Stelle die Verbrechen, die durch das Laogai-System an Teilen der chinesischen Bevölkerung verübt worden seien, auf eine Stufe mit denen in den Konzentrationslagern der Nazis (1933-1945), im sowjetischen Gulag (1917-1988) sowie den Killing Fields (1975-1979) in Kambodscha (siehe Abb. 12).

Der daran anschließende Ausstellungsabschnitt widmete sich schließlich dem Thema der Menschenrechtsverletzungen in den Zwangsarbeitslagern im gegenwärtigen China. Insbesondere wurde hier auf den illegalen, staatlich organisierten Organhandel aufmerksam gemacht, dessen größte Opfergruppe laut

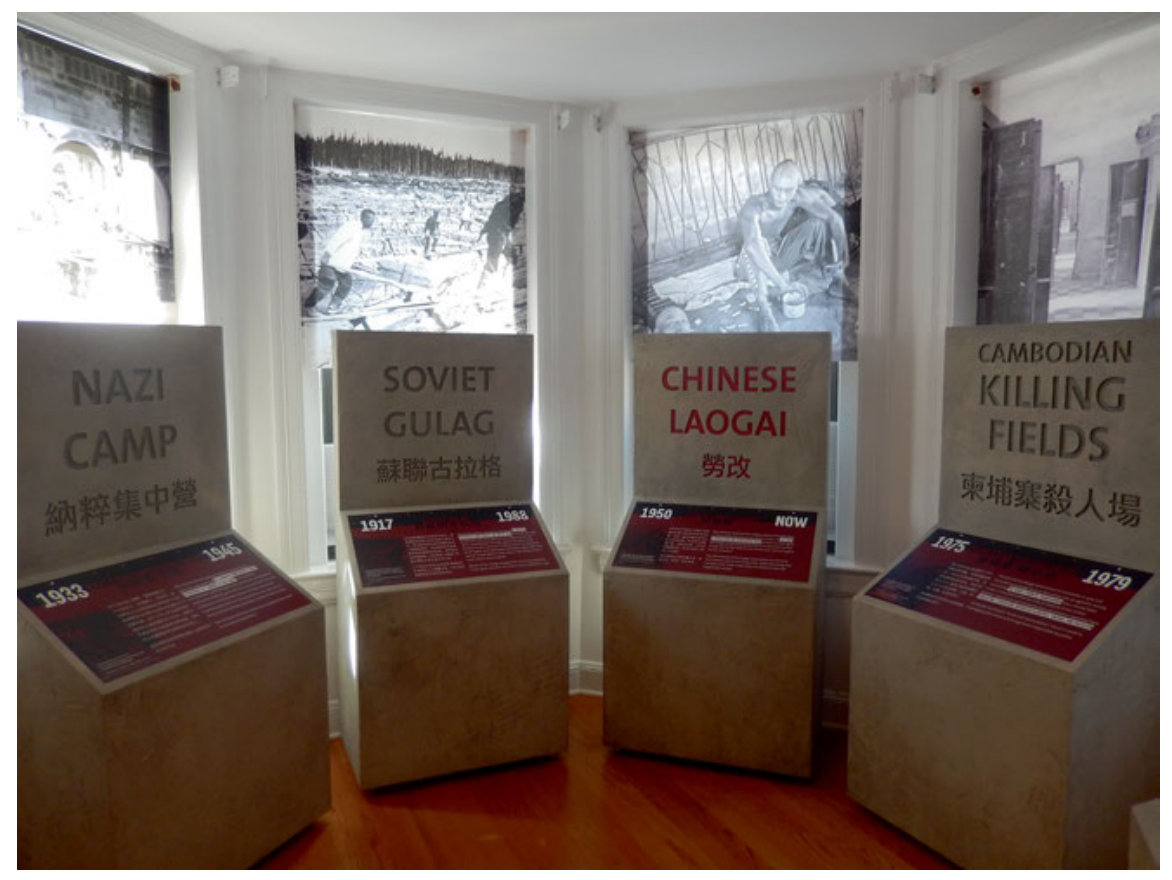

Abbildung 12: Das chinesische System der Zwangsarbeit im internationalen Vergleich (eigene Fotografie, Laogai-Museum, April 2016) 
Ausstellungstext die inhaftierten Anhänger der Falun-Gong-Bewegung seien. Demnach würden ihnen gegen ihren Willen gesunde Organe entnommen und durch die KPCh lukrativ an zahlungskräftige Patienten verkauft, teilweise komme es dafür sogar zu illegalen Exekutionen. Die wirtschaftliche Bedeutung der Zwangsarbeit war ebenfalls Bestandteil dieses Teils der Ausstellung. Dieser wies darauf hin, dass einige der in den Lagern hergestellten Produkte, wie Lichterketten, Büroartikel, Stofftiere oder bestimmte Sorten Tee ins Ausland verkauft werden würden. Dementsprechend richtete sich dieser Abschnitt insbesondere an ein internationales Publikum und beinhaltete einen Aufruf, den Kauf solcher Produkte künftig möglichst zu unterlassen, um eine Unterstützung des Zwangsarbeitslagersystems zu vermeiden.

Der letzte Teil der Ausstellung fungierte indes als alternativer Erinnerungsort für die Schicksalsgenossen Harry Wus, die dem chinesischen Laogai-System zum Opfer gefallen waren. Hier wurde der Kampf gegen das Vergessen insbesondere dadurch ersichtlich, dass auf einer großen Gedenktafel 399 Opfer des Laogai-Systems namentlich benannt wurden. Darüber hinaus gab es eine Wand mit Einzelportraits sowohl mit prominenten politischen Opfern der Kampagnen unter Mao, wie etwa die für ihre „Bluttagebücher“ bekannt gewordene Rechtsabweichlerin Lin Zhao 林昭, ${ }^{538}$ als auch mit Portraits prominenter Opfer des postmaoistischen China wie Liu Xiaobo. Neben dem Foto der Opfer der Menschenrechtsverletzungen der KPCh befanden sich Angaben zum Datum der Inhaftierung, zu den ihnen zur Last gelegten „Verbrechen“ und, falls sie im LaogaiSystem zu Tode gekommen sind, dem Sterbedatum. Der in diesem Museum geschaffene alternative Ort des Erinnerns wurde auf zwei Seiten von jeweils einem Schild gesäumt, die einerseits die Bedeutung des öffentlichen Erinnerns, andererseits die Intention des Gründers Harry Wu und die Leitgedanken des Museums zusammenfassten. Die Aussage „Die Stärke zu Erinnern“ (siehe Abb. 13) wies darauf hin, dass es Mut bedarf, sich dem staatlich verordneten Vergessen entgegenzustellen, wohingegen die Aussage „Kein Recht zu vergessen“ (siehe Abb. 14) als direkter Angriff auf die staatliche Erinnerungspolitik der VR China verstanden werden kann.

538 Lin Zhao hatte die KPCh während der Hundert-Blumen-Bewegung deutlich kritisiert und wurde aufgrund dessen zur Umerziehung durch Arbeit verurteilt. In der Zeit ihrer Haft schrieb sie Tagebücher und Essays, in denen sie Mao Zedong heftig kritisierte, indem sie ihr eigenes Blut als Tinte benutzte. Aufgrund der Schwere ihrer Verbrechen wurde sie schließlich im Jahr 1969 hingerichtet. Die „Bluttagebücher“ sind in den Archiven der Hoover Institution an der Stanford University einsehbar. Im Jahr 2018 wurden Teile ihrer „Bluttagebücher“ und ihre Lebensgeschichte auf Englisch veröffentlicht, siehe Lian 2018. 


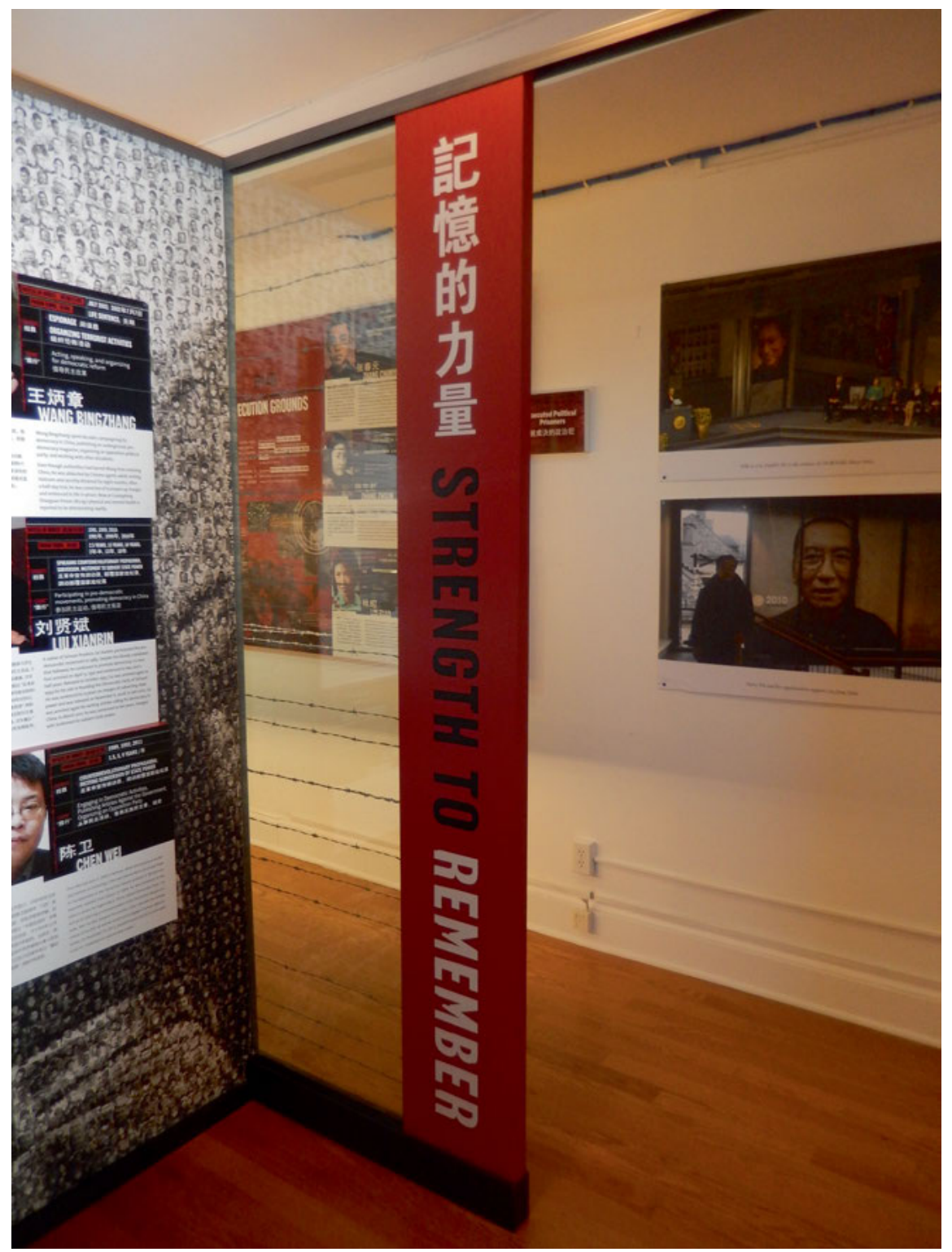

Abbildung 13: „Die Stärke zu erinnern“ (eigene Fotografie, Laogai-Museum, April 2016)

Insgesamt stellte das Laogai-Museum nicht nur einen Angriff auf die offizielle Geschichtsschreibung der KPCh dar, in der das Laogai-System kaum Berücksichtigung findet, sondern auch einen Akt der politischen Partizipation, indem es 


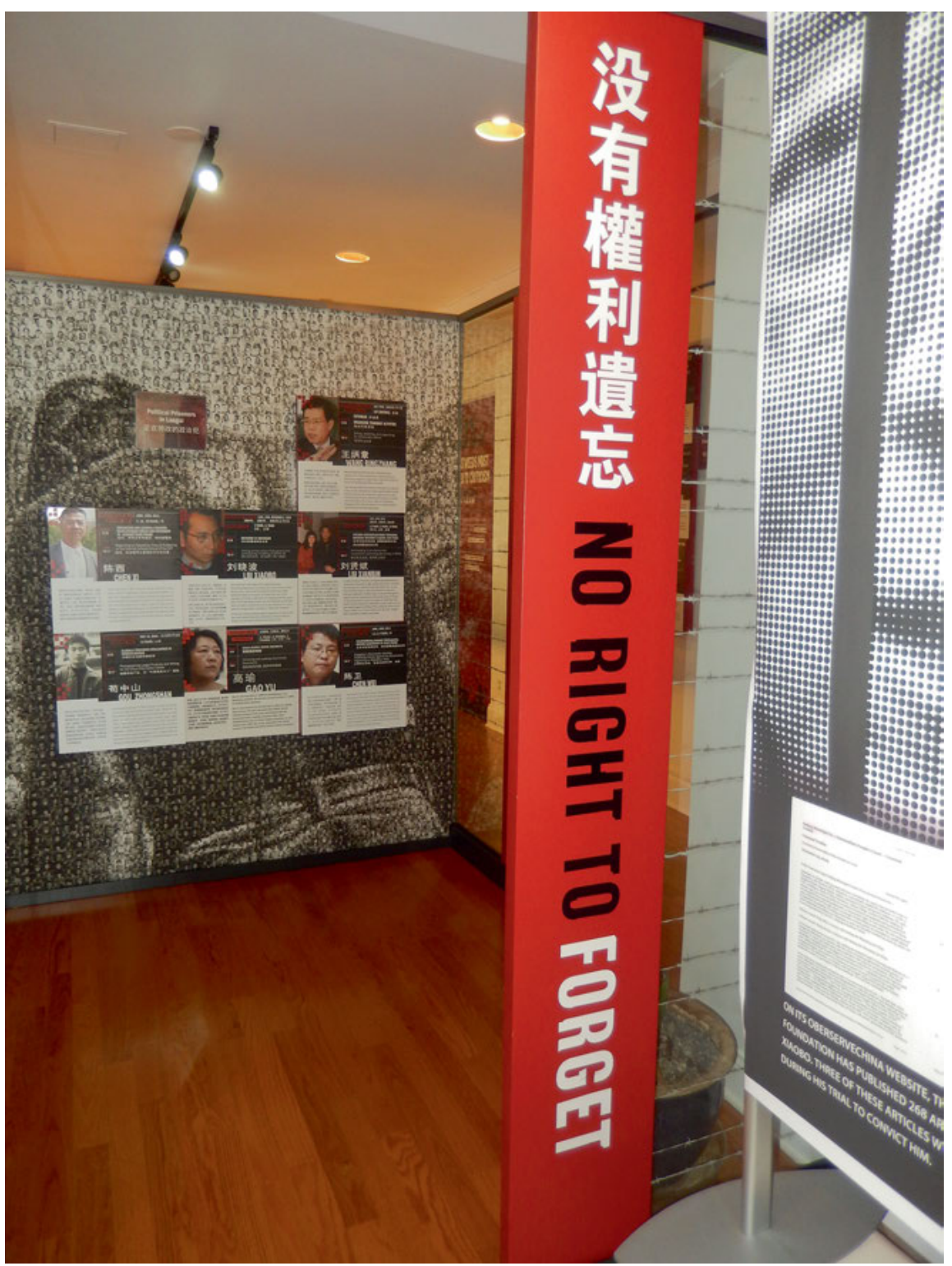

Abbildung 14: „Kein Recht zu vergessen“ (eigene Fotografie, Laogai-Museum, April 2016)

zum Beispiel den Westen dazu aufrief, sich aktiv den Menschenrechtsverletzungen entgegenzustellen. 
Museale Darstellungen wie diese können durchaus auch Gewicht im Kampf um das kollektive Gedächtnis haben, auch wenn die Eröffnung eines solchen Museums innerhalb Chinas nicht denkbar wäre. Eine Stadt wie Washington, D.C. zieht jährlich sehr viele chinesische Touristen, aber auch eine hohe Anzahl an Studierenden aus China an, die somit durchaus auch mit den Inhalten des Museums in Berührung kommen können. ${ }^{539}$

Insgesamt konnten die Zensurmaßnahmen der chinesischen Behörden die Akteure dieser Kategorie der Geschichtsschreibung, Zeitzeugen bzw. öffentliche Intellektuelle, nicht davon abhalten, weiterhin alternative Versionen der Vergangenheit $\mathrm{zu}$ verbreiten, und so konnten einige Veröffentlichungen der hier beschriebenen Kategorie nach und nach zu einer scharfen Waffe im Kampf um das kollektive Gedächtnis werden. Besonders problematisch aus Sicht der KPCh ist, dass sie, sobald die Narrative außerhalb Chinas veröffentlicht werden, zwar einen gewissen Einfluss auf deren Verbreitung in der VR China, nicht jedoch auf deren Inhalt nehmen kann.

\subsection{Persönliche Erinnerungen als Angriff auf die Herrschaftslegitimation der Partei?}

Auch wenn einige dieser von der Partei nicht tolerierten Narrative aufgrund eines allgemein geringeren Interesses an chinesischer Geschichte im Ausland nur eine geringe Auflage erzielen konnten, ${ }^{540}$ schafften es manche Publikationen, wie zum Beispiel die im Folgenden diskutierten, seit den 1990er Jahren durchaus immer wieder, großes Aufsehen innerhalb Chinas zu erregen. Dies gilt insbesondere für die nachfolgend diskutierten Memoiren, die in der VR China auf großes Interesse stießen und auf illegalen Wegen zahlreich verbreitet worden sind.

539 Alleine im Jahr 2017 sollen 324.000 Touristen aus China nach Washington, D.C., gereist sein. Siehe Rosen 2018, https://dcist.com/story/18/12/14/an-inside-look-at-the-effort-to-lure-chinesetourists-to-d-c/.

540 Dazu kann zum Beispiel die „Schwarze Serie“ (heise wenku 黑色文库) gezählt werden, die von der Laogai Research Foundation herausgegeben wird und im Wesentlichen Erinnerungen von ehemaligen Opfern des Laogai-Systems beinhaltet. Aufgrund ihrer geringen Auflage können die Bücher dieser Serie seit Januar 2019 auch kostenlos online gelesen werden. Die Stiftung erhofft sich dadurch, die Verbreitung der Inhalte zu erhöhen. Siehe Laogai Research Foundation 2019, https://laogairesearch.org/publications/. 


\subsubsection{Dr. Li Zhisui - Ich war Maos Leibarzt}

Im Jahr 1994 veröffentlichte Li Zhisui 李志绥, zwischen 1955 bis 1976 Maos Leibarzt und somit ein enger Weggefährte des Vorsitzenden, mit dem Buch Ich war Maos Leibarzt seine persönlichen Erinnerungen an die Zeit an Maos Seite und seine subjektiven Eindrücke der politischen Entwicklungen Chinas aus dem inneren Zirkel der Macht heraus. Der Zeitpunkt der Veröffentlichung dieses Buches, welches in weiten Teilen ein überaus negatives Licht auf die Ikone Mao wirft, hätte für die KPCh kaum ungünstiger sein können, fiel sie doch in eine Phase, in der sie nach den Studierendenprotesten 1989 noch um ihre Herrschaftslegitimation kämpfte. Ein solch offener Angriff auf eine ihrer wichtigsten historischen Figuren stellte somit auch einen offenen Angriff auf die Machthaber Chinas der 1990er Jahre dar.

Obwohl das Buch, im Gegensatz zu den anderen analysierten Quellen dieser Arbeit, zunächst nicht auf Chinesisch, sondern zuerst auf Englisch erschienen ist, ${ }^{541}$ sollte es dennoch eine wichtige Rolle im Kampf um das kollektive Gedächtnis in der VR China spielen. Denn in den 1990er Jahren, in denen das Bild Maos in der chinesischen Gesellschaft, trotz des Aufkommens einzelner kritischer Stimmen, im Allgemeinen sehr positiv gewesen ist, stieg das Interesse an Details aus dem Leben des Vorsitzenden zunehmend. Und so wurde das Buch nicht nur zu einem Bestseller in Ländern wie den USA, Großbritannien oder Taiwan, sondern auch die Nachfrage nach der chinesischen Version des Buches stieg stetig, welche, trotz Zensur, eine weite Verbreitung über den Schwarzmarkt des chinesischen Festlandes finden würde. ${ }^{542}$ Die Aufmerksamkeit, die das Buch Mitte der 1990er Jahre auf sich zog, dürfte auch deshalb so groß gewesen sein, weil fast zeitgleich zu seiner Erstveröffentlichung in den USA eine viel beachtete BBCDokumentation über den Arzt Li Zhisui ausgestrahlt worden ist, welche die chinesischen Machthaber sehr verärgert hat. ${ }^{543}$ Aufgrund der Tatsache, dass immer mehr junge Chinesen in den 1990er Jahren im Ausland studierten bzw. die englische Sprache erlernten, dürfte die Debatte um dieses Buch nach und nach auch auf diesem Wege nach China vorgedrungen sein. Insgesamt sollte das Buch einen wichtigen Beitrag zu einer neuen öffentlichen Debatte über die historische Einordnung Mao Zedongs in China leisten.

541 Das 1994 in den USA erschienene Buch trägt den Titel The Private Life of Chairman Mao. Die nachfolgende Analyse bezieht sich auf die kurz darauf erschienene deutsche Version.

542 Jolly 2000, S. $487 \mathrm{f}$.

543 Darnton 1993, https://www.nytimes.com/1993/12/19/world/china-protests-bbc-documenta ry-about-mao.html?mtrref=www.google.com\&gwh=EBDCEED53D038455FB66D31D

DE80206D\&gwt=pay\&assetType=REGIWALL. 
Die Darstellungen des Buches werfen, sehr zum Missfallen der KPCh, nicht nur ein neues Licht auf den verstorbenen Vorsitzenden, sondern auch auf einige „historische Fehler“, die der Partei als Ganzes schaden könnten, wie die Kampagne gegen Rechtsabweichler, worauf sich die nachfolgende Analyse hauptsächlich bezieht, den Großen Sprung nach vorn oder die Kulturrevolution. Die Erläuterungen Lis gehen einher mit sehr indiskreten und unerfreulichen Schilderungen zu Maos Privatleben und seinem Gesundheitszustand.

Doch nicht nur in China selbst hat Ich war Maos Leibarzt heftige Kontroversen ausgelöst, auch unter westlichen Chinahistorikern ist das Buch sehr umstritten. Andrew Nathan zum Beispiel, Professor für Politikwissenschaften an der New Yorker Columbia University und Verfasser des Vorwortes, schreibt dem Buch eine sehr hohe Bedeutung für das Verständnis Mao Zedongs zu: „Noch kein anderer Diktator ist so genau charakterisiert worden wie Mao in den Memoiren des Mannes, der zweiundzwanzig Jahre lang sein Leibarzt war. “544 Andere anerkannte Chinawissenschaftler hingegen stehen den Darstellungen Li Zhisuis weitaus kritischer gegenüber. Gegenstand der Kritik ist häufig die nach Meinung der Wissenschaftler zu undifferenzierte negative Darstellung des Wirkens Mao Zedongs. Timothy Cheek etwa kritisiert die simple Denunzierung Maos als teuflischen Herrscher. ${ }^{545}$ Und Frederick Teiwes kritisiert, dass das Buch teilweise historische Ungenauigkeiten aufweise und Li Zhisui gewisse historische Zusammenhänge falsch eingeordnet bzw. missinterpretiert habe. Als Beispiel nennt er hier die im Buch beschriebene Rolle Zhou Enlais, der durch Li als willenloser Sklave Maos dargestellt werde. Dennoch räumt Teiwes ein, dass er mit seinen Darstellungen zumindest Einblicke in die Atmosphäre Zhongnanhais 中南海, dem Hauptsitz der KPCh und der Regierung, jener Jahre gewährt. ${ }^{546}$

Inhaltlich basiert das Buch auf seinem persönlichen Tagebuch, welches der Autor ab dem Jahr 1954, als er als Arzt nach Zhongnanhai gekommen war, geführt habe. Es beschreibt seine persönlichen Erinnerungen an die politischen Ereignisse ab Mitte der 1950er Jahre bis kurz nach dem Sturz der Viererbande 1976. Die Schilderungen beschränken sich dabei weitgehend auf den Blickwinkel, den er in jenen Jahren selbst innegehabt hatte, nämlich den des Arztes, weshalb einige politische Ereignisse ausgelassen oder nur lückenhaft in den historischen Kontext eingeordnet werden. Ebenso beschränken sich die Erläuterungen auf jene Machthaber bzw. Weggefährten, mit denen er in persönlichem Kontakt gestanden hat - das waren natürlich vorwiegend der Vorsitzende Mao selbst wie auch seine

544 Li 1994, S. 9.

545 Li 2002b, S. 9.

546 Teiwes 1996, S. $178 \mathrm{ff}$. 
Frau Jiang Qing. Zu anderen hochrangigen Parteikadern wie Liu Shaoqi, Zhou Enlai oder Deng Xiaoping hatte er, auch aufgrund der Zurückgezogenheit Maos, nur sehr selten Kontakt. Ihre jeweiligen Rollen in den politischen Ereignissen werden deshalb zwar erwähnt, jedoch meist nicht intensiv analysiert. Li Zhisui schreibt sich deshalb die Rolle des Beobachters und nicht die eines Akteurs des politischen Geschehens jener Jahre zu. Das heißt, dass die Darstellungen des Autors nicht nur äußerst subjektiv, sondern auch sehr selektiv sind, da diese davon geprägt wurden, welche Einsichten ihm Mao oder andere Weggefährten gewährten. In der Mitte des Buches erwähnt Li nur sehr beiläufig, auf welchen Informationen seine Wahrnehmungen jener Zeit beruhten:

Wenn ich überleben wollte, musste ich mich ohnehin aus der Politik heraushalten. Von den großen Veränderungen im Land erfuhr ich nur durch Mao selbst, aus den parteiinternen Dokumenten, die ich in die Hand bekam, und aus den Berichten, die mir mein Freund Tian Jiaying, Maos politischer Sekretär, zuspielte..$^{547}$

Die Art der Wiedergabe der Reflexion seiner Erinnerungen an Mao und die politischen Ereignisse sind darüber hinaus von verschiedenen weiteren Faktoren geprägt. Zum einen muss man berücksichtigen, dass der Autor zu dem Zeitpunkt, als er das Buch schrieb, bereits in die USA ausgewandert war. Die Veränderung des sozialkulturellen Kontextes kann immer auch mit einer Veränderung der Art der Reflexion der Vergangenheit einhergehen. Außerdem ist Li Zhisui kein gelernter Schriftsteller und auch kein Wissenschaftler, weswegen er das Buch mit Hilfe von Anne F. Thurston, einer amerikanischen Politikwissenschaftlerin, geschrieben hat, was ebenfalls zu Veränderungen der Darstellung der Vergangenheit geführt haben dürfte. Zum anderen muss aber auch die Tatsache, dass er als Arzt der Wir-Gruppe der Mediziner angehört, berücksichtigt werden. Gleichzeitig gehört er als Arzt natürlich auch zur Gruppe der Intellektuellen, wodurch auch die Beschreibungen der Ereignisse der Kampagne gegen Rechtsabweichler geprägt sind. Seine starke Identifikation mit seinem Beruf und anderen Vertretern seiner Berufsgruppe wird in dem Buch insgesamt immer wieder deutlich und beeinflusst erkennbar auch die inhaltlichen Schwerpunkte der Darstellungen. Ein weiterer entscheidender Faktor ist, wie er selbst andeutet, auch sein familiärer Hintergrund und damit in Zusammenhang stehende persönliche Erfahrungen aus der Kindheit und Jugend, insbesondere dem schlechten Verhältnis zu seinem Vater, der ein Mitglied der Guomindang gewesen ist. Er habe sich stets für dessen Umgang mit Frauen und seinem Streben nach Macht geschämt, was letztlich dazu geführt habe, dass er selbst damals mit den Kommunisten sympathisierte. Maos

547 Li 1994, S. 186. 
ausschweifendes Privat- bzw. Sexualleben, welches sehr detailliert beschrieben wird, habe ihn an den ungeliebten Vater erinnert:

Ich schämte mich für ihn und war entschlossen, mich als Arzt im Dienste der Menschheit aufzuopfern. Die Stellung meines Vaters innerhalb der Guomindang-Regierung war einer der Gründe, weshalb ich die Nationalisten verabscheute. Vielleicht trug auch die Verachtung für die moralische Schwäche meines Vaters dazu bei, dass ich später über Maos Privatleben so entsetzt war. ${ }^{548}$

Was die Intention zur Veröffentlichung des Buches betrifft, lässt Li im Wesentlichen zwei Ebenen erkennen: die der Information und die des Schreibens gegen das Vergessen. Im Vorwort erläutert er, dass er den Lesern Einblicke in das Leben des Diktators Mao gewähren möchte, um ihnen eine Anregung zu geben, „ihre eigenen Ideale und ihre Freiheiten wieder höher zu schätzen“. ${ }^{549}$ In diesem Zusammenhang legt er dar, wie die Ideale, die er in den Jahren nach der Gründung der VR China hatte, ebenso wie seine damit verbundenen Hoffnungen in die Partei und Mao Zedong, sich nach und nach in Luft aufgelöst hätten. Für Li stehe der Tod Maos damit sinnbildlich für das Auflösen dieser Hoffnungen von einem neuen, besseren China:

Anfangs hatte ich Mao bewundert. Er war der Retter Chinas, der Messias des Landes. Aber das war lange her. Mein Traum von einem neuen China, in dem alle Menschen gleich sein würden und die Ausbeutung ein Ende hätte, war schon vor Jahren zerstört worden. Ich hatte kein Vertrauen mehr zur Kommunistischen Partei, deren Mitglied ich immer noch war. Eine Ära ist zu Ende, dachte ich, während ich auf die gerade Linie auf dem Elektrokardiographen starrte. Maos Zeit ist vorbei. ${ }^{550}$

Er beschreibt auch seine Gefühlslage in Bezug auf die chinesischen Machthaber und die Aufbruchsstimmung, die insbesondere Mao verbreitet hatte und die so typisch war für die Mehrheit seiner Landsleute in jenen Tagen rund um die Ereignisse der Ausrufung der VR China am 01. Oktober 1949, die er aus nächster Nähe miterlebt hatte:

Obwohl sich die ganze Aufmerksamkeit auf Mao Zedong konzentrierte, war seine Haltung würdevoll und bescheiden, und er zeigte keine Spur von Arroganz. Viele Male hatte ich Jiang Jieshi auf dem Höhepunkt seiner Macht in der Öffentlichkeit erlebt; er war immer unnahbar gewesen und hatte von allen Unterwürfigkeit erwartet. [...] Ich war so stolz auf China, so voller Hoffnung und so froh, dass Ausbeutung, Leid und ausländische Aggressionen ein

548 Ebd., S. 57.

549 Ebd., S. 17.

550 Ebd., S. 30. 
Ende haben würden. Für mich gab es keinen Zweifel, dass Mao der große Führer der Revolution war, der Schöpfer der neuen chinesischen Geschichte. ${ }^{551}$

Dies steht in einem deutlichen Gegensatz zu seinen nachfolgenden Schilderungen seiner Erinnerungen an die Begegnungen mit dem Vorsitzenden.

Seine Intention, das Buch gegen das Vergessen der Geschichte und für den zukünftigen gesellschaftlichen Fortschritt zu schreiben, formuliert er im letzten Kapitel. Dabei deutet er auch an, dass die Veröffentlichung der „Wahrheit“ innerhalb Chinas auf offiziell legitimiertem Wege nicht möglich gewesen wäre. Dies könnte man auch dahingehend deuten, dass er zu einer Selbstzensur, wie sie für eine Tolerierung durch die KPCh notwendig gewesen wäre, nicht bereit gewesen ist:

Später drängten mich auch viele Herausgeber von Zeitungen und Zeitschriften, meine Erinnerungen niederzuschreiben. Ich lehnte jedes Mal ab. Die Wahrheit konnte ich nicht schreiben, und lügen wollte ich nicht. Lillian (Anm.: seine Frau) gelang es schließlich, mich zu überzeugen. In den letzten Tagen im Krankenhaus, bevor sie ins Koma fiel, bat sie mich, dieses Buch zu schreiben - als Dokument für unsere Kinder, unsere Enkel und die Generationen nach uns sowie als Beschreibung des Lebens an Maos „Hof“. Ich habe für dieses Buch teuer bezahlt. Mein Traum, ein bedeutender Neurologe zu werden, hat sich nicht erfüllt, und meine Hoffnung auf ein neues China wurde zunichte gemacht. Ein richtiges Familienleben blieb mir versagt, und jetzt ist Lillian tot. Als das Hauptbüro der Sicherheitskräfte mich im Jahre 1990 schriftlich darum bat, meine Wohnung übernehmen zu dürfen, lehnte ich ab. Zwei Jahre später wurde die Wohnung konfisziert. Ich richtete Protestschreiben an Yang Shangkun (den damaligen Präsidenten der Republik), Yang Dezhong (den Leiter des Hauptbüros der Sicherheitskräfte), Chen Mingzhan (den Gesundheitsminister) und Jiang Zemin (den Führer der Kommunistischen Partei), erhielt jedoch keine Antwort. Obwohl ich mein ganzes Berufsleben Mao und China gewidmet habe, bin ich heute staaten- und heimatlos, unwillkommen im eigenen Land. Ich schreibe dieses Buch aus Trauer um Lillian und um jeden, der die Freiheit liebt. Es soll an die schrecklichen Folgen der Diktatur Maos erinnern, und daran, dass rechtschaffende und begabte Menschen unter seinem Regime gezwungen wurden, ihrem Gewissen zuwiderzuhandeln und ihre Ideale zu opfern, um zu überleben..$^{52}$

Insgesamt gehen die Beschreibungen der historischen Ereignisse jener Jahre einher mit detaillierten Erläuterungen des sich immer wieder verändernden Gesundheitszustandes des Vorsitzenden und teilweise auch seiner Frau Jiang Qing. Die medizinischen Befunde Lis ziehen sich dabei wie ein roter Faden durch das Buch und lassen es fast zu einem „physischen“ Text werden. Besonders deutlich

551 Ebd., S. 73.

552 Ebd., S. $657 \mathrm{f}$. 
wird dies, als er erläutert, dass Mao seit Beginn seiner Tätigkeit als sein Leibarzt an Neurasthenie gelitten habe, einer Krankheit, die mit langanhaltenden Phasen von Erschöpfung und Ermüdung einhergeht, und die, so merkt Li an, in anderen gesellschaftlichen Strukturen wie in den USA überhaupt nicht mehr auftrete. Hier verknüpft er die Beschreibung der Erkrankung Maos mit einer Beschreibung des Zustands der damaligen chinesischen Gesellschaft und des Kommunismus:

\begin{abstract}
Mit der Zeit erschien mir Neurasthenie als eine typisch kommunistische Krankheit: die Folge des Eingesperrt seins in einem System, aus dem es kein Entrinnen gab. 1952 wurde ich zum ersten Mal auf dieses Syndrom aufmerksam. Nachdem mein Bruder während der Drei-AntiKampagne heftig attackiert worden war, litt er an schwerer Neurasthenie, die sich vor allem in hohem Blutdruck äußerte. Nach der Kampagne gegen Rechtsoppositionelle im Jahr 1957, in deren Verlauf so viele Unschuldige fälschlich angeklagt wurden, nahmen die Fälle von Neurasthenie drastisch zu. Meines Wissens war die Krankheit unter der Guomindang-Regierung nicht so verbreitet gewesen, denn damals hatte man immer eine Möglichkeit zur Flucht. Aber unter den Kommunisten gab es kein Entkommen. ${ }^{553}$
\end{abstract}

Die Ursache für Maos Erkrankung sieht Li in der sehr starken paranoiden Persönlichkeit Maos, die aber auch mit den politischen Strukturen Chinas einhergehe: „Maos immer wiederkehrende Anfälle beruhten auf seiner Angst, andere hochrangige Politiker stünden nicht loyal zu ihm und er könne nur wenigen in-

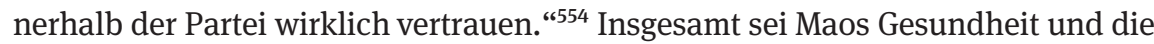
Politik des Landes nicht selten miteinander verknüpft gewesen.

Doch auch Li selbst, der immer wieder sowohl unter dem Druck, für Mao arbeiten zu müssen, als auch unter der für Intellektuelle allgemein politisch schwierigen Lage gelitten habe, beschreibt, dass politische Veränderungen zum Negativen mitunter auch mit Veränderungen seiner körperlichen Konstitution einhergegangen seien. Insbesondere habe sich dies rund um die Lushan-Konferenz 1959 gezeigt, als er, wie er sagt, aufgrund des Großen Sprungs nach vorn und der zunehmenden Spaltung der Kommunistischen Partei an einem Magengeschwür erkrankt sei. Eine Verbesserung sei dann just zu dem Zeitpunkt eingetreten, als er Lushan zur Behandlung in einem Pekinger Krankenhaus verlassen habe:

Sobald sich das Auto über die gewundene Bergstraße vom Konferenzort entfernte, löste sich meine Anspannung. Ich ließ eine von inneren Spaltungen bedrohte Partei zurück. Meine Träume für China und die Partei hatten sich verflüchtigt. Mein Bild von Mao war zerschmettert worden. Meine einzige Hoffnung war, dass ich mich selbst aus der Katastrophe retten konnte. Je weiter wir uns von Lushan entfernten, desto weniger Schmerzen bereitete 
mir mein Magengeschwür. In Lushan hatte ich nicht schlafen können, aber schon als das Flugzeug abhob, fiel ich in einen tiefen Schlummer. ${ }^{555}$

Obwohl die Medizin und die Darstellung des Körperlichen einen hohen Stellenwert in Li Zhisuis Memoiren einnehmen, geht er, indem er diese immer wieder mit den politischen Geschehnissen jener Jahre verknüpft, auch auf einige „historische Fehler" ein, die sich während seiner Jahre als Maos Leibarzt zugetragen hatten. Dabei liefert er, wie bereits angedeutet, keinen allumfassenden Überblick über alle Ereignisse jener Jahre, sondern geht höchst selektiv vor. Die Kampagne gegen Rechtsabweichler nimmt allerdings einen besonderen Stellenwert ein, da sie die erste Kampagne gewesen sei, die er aus erster Hand mitbekommen habe. Er benennt die Kampagne bzw. die ihr vorausgegangenen Ereignisse des Jahres 1956 als Wendepunkt sowohl für das gesamte Land als auch für die Intellektuellen und damit für ihn selbst.

Für ihn persönlich habe das Jahr 1957 unter anderem deswegen einen Wendepunkt dargestellt, weil Mao ihn aktiv in die Kampagne habe miteinbeziehen wollen. Der Vorsitzende habe sich nicht mehr damit zufriedengegeben, dass er sich nur auf das Medizinische konzentrierte und sich aus allem Politischen heraushalten wollte. Sehr zum Unbehagen Lis habe Mao ihn an das Union Medical College in Peking geschickt, um ihn als Spion Bericht über die Situation vor Ort und die politische Einstellung der führenden Mitarbeiter erstatten zu lassen. Auch wenn Li dies nicht behagt habe, tat er wie ihm geheißen und berichtete, dass sich einige Ärzte kritisch über die Partei geäußert hätten. Zu Beginn der Kampagne habe Li noch an die Partei und an Mao geglaubt und die offene Kritik an ihm für eine Dummheit gehalten. Im Laufe der kommenden Monate würde sich sein Blick auf die Partei und auf den Vorsitzenden jedoch grundlegend verändern. Wie er bereits zu Beginn des Buches andeutet, hätten jene Monate ein sukzessives Schwinden seiner Hoffnungen in die Partei eingeläutet. Während früherer politischer Maßnahmen gegen Intellektuelle, wie etwa während der Kampagne gegen Konterrevolutionäre, habe er die Verfolgungen, von denen er mitbekam, noch als Einzelfälle abgetan:

Anfangs, vor Beginn der Verfolgungen, erschien es mir ganz selbstverständlich, dass China künftig von der Kommunistischen Partei regiert werden sollte. Ich war begeisterter Anhänger der Partei und sah in ihr die Hoffnung auf ein neues China. In Australien war ich ziellos umhergeirrt, erst die Politik der Einheitsfront hatte mir die Augen geöffnet. Im neuen China waren meine Kenntnisse gefragt, wir Intellektuellen würden Macht und Ansehen besitzen.

555 Ebd., S. 354. 
Anzeichen, die darauf hindeuteten, dass die Partei nicht meinen Erwartungen entsprach, tat ich als Einzelfälle ab. ${ }^{556}$

Die Vorfälle ab dem Jahr 1957 habe er dann jedoch nicht mehr ignorieren können und ihm sei nach und nach gewahr geworden, dass Mao das Leben seiner Landsleute nichts bedeute. Somit habe der für ihn wahrgenommene Wendepunkt, das heißt die Kampagne gegen Rechtsabweichler, nicht nur für die Intellektuellen, sondern auch für ihn selbst insofern nachhaltige Veränderungen mit sich gebracht, als er fortan befürchtet habe, dass sein Klassenhintergrund - sein Vater war einst ebenfalls ein angesehener Arzt gewesen - und sein Status als Intellektueller immer wieder zu Problemen führen würden:

Ich würde immer ein Intellektueller bleiben, ein Arzt aus einer „Klasse von Ausbeutern“, und deshalb eine problematische Person, ein Objekt für „Integrations-, Verwertungs- und Reformmaßnahmen“. Mein Wert für die Partei beruhte einzig und allein auf meinen medizinischen Fähigkeiten. ${ }^{557}$

Die latente Angst, dass er als Intellektueller jederzeit in Maos Gunst sinken und Gegenstand politischer Verfolgungen werden könnte, habe sich bis zum Tod des Vorsitzenden nicht gelegt. Retrospektiv vertritt er die Ansicht, ähnlich wie auch Hu Ping rund zehn Jahre später, dass die Kampagne gegen Rechtsabweichler die gesellschaftlichen Grundlagen für die Kulturrevolution gelegt habe und man sie deshalb als historischen Wendepunkt für das ganze Land ansehen könne.

Li Zhisui nimmt auch eine kurze historische Einordnung der Kampagne gegen Rechtsabweichler vor, wobei er sich dabei vorwiegend nicht auf historische Quellen oder Arbeiten von Historikern stützt, sondern auf seine eigenen Beobachtungen und Gespräche mit Mao und anderen damaligen Weggefährten. Insbesondere die von Mao angestrebte Säuberung der Partei, mit der er sich unliebsamer politischer Gegner entledigen wollte, als auch die Vorfälle in Polen und Ungarn, hätten dazu geführt, dass Mao die Intellektuellen schließlich zur Kritik aufgerufen habe. Li stellt die KPCh als eine in nahezu allen politischen Fragen zutiefst gespaltene Partei dar, was ihm aus den vielen Gesprächen mit Mao deutlich geworden sei. Und deshalb sollte die Hundert-Blumen-Bewegung eher dazu eingesetzt werden, seine eigene Macht zu stabilisieren, als zu einem gesamtgesellschaftlichen Fortschritt zu kommen und der Spaltung von Volk und Partei entgegenzuwirken. Doch genau dabei habe Mao einen entscheidenden, 
wenn auch aus Lis damaliger Sicht durchaus nachvollziehbaren Fehler begangen, indem er die Haltung der Intellektuellen falsch eingeschätzt habe:

\begin{abstract}
Maos Taktik, die Diskussion unter den Intellektuellen anzuregen, „hundert Blumen blühen und hundert Schulen miteinander wetteifern“ zu lassen, beruhte auf der riskanten Annahme, dass es nur wenige echte „Konterrevolutionäre“ gab, dass Aufmüpfige wie Hu Feng für immer zum Schweigen gebracht worden waren und dass andere Intellektuelle nur diejenigen Personen und Praktiken kritisieren würden, die Mao zu reformieren beabsichtigte. Er hatte Grund zur Annahme, dass seine Taktik erfolgreich sein würde. Denn auch bei Begegnungen mit Vertretern der „demokratischen Parteien“, wurde er stets mit unterwürfigen Schmeicheleien überhäuft - nicht anders als auf unserer Sommerreise im Jahr 1956, auf der er mit provinziellen kommunistischen Parteiführern zusammengetroffen war. Nachdem Hu Feng zum Schweigen gebracht worden war, durfte man vermuten, dass die verbleibenden loyalen Intellektuellen Maos Vorgaben folgen würden. ${ }^{558}$
\end{abstract}

Nachdem erkennbar geworden sei, dass die kritischen Stimmen deutlicher ausfielen, als von Mao erwartet, habe er im Mai 1957 mit Li ganz offen darüber gesprochen, dass er nun eine Falle legen und „die Schlangen aus ihren Löchern holen" werde - und zwar innerhalb und außerhalb der Partei. Dies habe er, so Li, jedoch in erster Linie nicht zum Schutz der Partei getan, wie es etwa in der Resolution beschrieben wurde, sondern vor allem aufgrund seiner persönlichen Eitelkeiten:

Aus heutiger Sicht halte ich Maos Kampagnen von 1956 und 1957 für eine fehlgeschlagene Kulturrevolution. Heute verbinden wir mit dem Jahr 1957 hauptsächlich die Schrecken der Anti-Rechts-Kampagne, obwohl die Gegner Maos ursprünglich nicht die Rechten außerhalb der Partei waren, sondern führende kommunistische Funktionäre, die ihn gekränkt, in seiner Macht beschnitten und vor seinen utopischen sozialistischen Träumen gewarnt hatten. Mao befürwortete die Angriffe auf seine Gegner, aber wollte das sozialistische System und den Führungsanspruch der Kommunistischen Partei nicht in Frage gestellt sehen. ${ }^{559}$

Was die Verantwortlichkeit für die Kampagne gegen Rechtsabweichler betrifft, die er eindeutig als „historischen Fehler“ einordnet, schreibt er diesen Fehler somit eindeutig Mao zu. Dennoch erwähnt er, dass Deng Xiaoping derjenige war, der für die Umsetzung der Kampagne verantwortlich gewesen sei. Zum damaligen Zeitpunkt sei ihm das jedoch nicht bewusst gewesen, was auch an der Isolation Maos gelegen habe, weshalb auch Li selbst den damaligen Generalsekretär fast nie zu Gesicht bekommen und keinen Überblick über sein politisches Handeln erhalten habe:

558 Ebd., S. 216f.

559 Ebd., S. 225 f. 
Deng Xiaoping war für die Organisation der Anti-Rechts-Kampagne verantwortlich. Deng hatte Mao auf dem Achten Parteikongress durch seine Rücktrittsempfehlung verärgert, aber er gehörte zu den Parteifunktionären, denen Mao hartes Durchgreifen zutraute. Erst viel später erfuhr ich, mit welcher Besessenheit Deng die Anti-Rechts-Kampagne leitete und wie brutal er diejenigen attackierte, die den Primat der Partei in Frage gestellt hatten. ${ }^{560}$

Li Zhisui betrachtet die Kampagne jedoch keineswegs distanziert respektive losgelöst von seiner eigenen Verantwortlichkeit. Auch wenn er als Arzt natürlich keine Verantwortung für die Gestaltung der Politik getragen hat und er politisch auch nicht so aktiv geworden ist, wie Mao sich das gewünscht hätte, setzt er sich in seinen Memoiren dennoch kritisch mit seiner eigenen Rolle auseinander. Wiederholt sucht er nach einer Rechtfertigung für seine Blindheit bezüglich des Umgangs mit den Intellektuellen und der Tatsache, dass so viele unschuldig zur Umerziehung durch Arbeit verurteilt worden waren, indem er beteuert, dass ihm die Tragweite dessen damals nicht bewusst gewesen sei und er dem Vorsitzenden zu Beginn der Kampagne noch blindes Vertrauen geschenkt habe:

Selbst als sich die Anti-Rechts-Kampagne ausbreitete, erfasste ich die Tragweite des Geschehens noch nicht. Ich wusste nicht, wie viele Menschen zur Umerziehungsarbeit verurteilt wurden und welche Qualen dies für sie bedeutete. Aus Maos Worten gewann ich sogar den Eindruck, der Vorsitzende sei seinen Feinden gegenüber großmütig und wolle ihnen eine Chance zum Umdenken geben. Als Mao mir mitteilte, die Hinrichtung seiner Gegner komme für ihn nicht in Frage, schenkte ich ihm Glauben. Ich unterstützte Mao und die AntiRechts-Kampagne. Mao war gut, die Kommunistische Partei war gut, und beide hatten China gerettet. ${ }^{51}$

Auch wenn sich sein Blick auf die Partei bereits im Laufe der Kampagne gegen Rechtsabweichler verändert habe, habe er erst im Jahr 1960 begriffen, dass sie sehr viele unschuldige Opfer gefordert hatte. Der Text macht deutlich, dass er ob seiner Naivität und der Tatsache, dass er damals nicht anders gehandelt und letztlich sogar weggesehen habe, eine große Schuld verspürt. Dennoch rechtfertigt er dies, indem er auf die Ausweglosigkeit seiner damaligen Lage hinweist:

Ich bin froh, dass ich Mao damals nicht verstand, dass ich den Umfang seiner Säuberungsaktion nicht überschaute, dass ich nicht wusste, welch schreckliches Leid anderen Intellektuellen widerfuhr und wie viele Menschen ums Leben kamen. Ich hatte so oft versucht, aus Maos Zirkel auszubrechen, und immer wieder hatte er mich zurückgeholt. Jetzt saß ich hoffnungslos in der Falle. Was hätte ich tun können, wenn ich gewusst hätte, was sich außerhalb meines schützenden Kokons abspielte? Eine chinesische Redensart lautet nande

560 Ebd., S. 225.

561 Ebd., S. 232f. 
hutu, was bedeutet, dass es manchmal nicht einfach ist, naiv zu sein, manchmal jedoch auch ein Glück. Aus heutiger Sicht weiß ich, dass ich damals naiv war und naiv sein musste. Das war meine einzige Überlebenschance. ${ }^{562}$

Das von Li Zhisui geschaffene Narrativ um die Kampagne gegen Rechtsabweichler stellt einen deutlichen Kontrast zur offiziellen Deutung der Kampagne in der 1981er Resolution dar. Dennoch dürften für die Zensurbehörden nicht allein die von Li Zhisui geschaffenen historischen Zusammenhänge problematisch gewesen sein - auch in China legal veröffentlichte Memoiren sprechen zum Beispiel die Verhaftung unzähliger Unschuldiger an -, sondern in erster Linie der Ton, der in diesem Zusammenhang angeschlagen wird. Er greift dabei nicht nur den Gründer der VR China direkt an, sondern er beschreibt die Partei zwischen den 1950er und 1970er Jahren insgesamt als zutiefst zerstritten, ineffektiv und korrupt. Die Spaltung der Partei war ein Thema, das in den 1990er Jahren, als die Legitimation der KPCh noch recht volatil gewesen ist, im öffentlichen Diskurs eher vermieden werden sollte, hatte Deng Xiaoping bereits einige Jahre zuvor doch das Ideal der kollektiven Führung für so wichtig erklärt. Somit drohte das Buch durchaus auch, eine Gefahr für die Herrschaftslegitimation der Partei in jenen Jahren darzustellen.

Insgesamt wartet das Buch mit einer Reihe weiterer Tabubrüche auf und landete sicherlich nicht nur aufgrund der Darstellungen der Kampagne gegen Rechtsabweichler auf der „schwarzen Liste“. Denn auch wenn Mao in der KPCh selbst durchaus kritisch bewertet worden ist, dürften neben der ausführlichen Beschreibung seines schlechten Charakters durch Li auch dessen Erläuterungen zu seinem ausschweifenden Sexualleben sowie die detaillierten Berichte zu seinem Gesundheitszustand, wie etwa seiner Hodenretention oder dem Zustand seines Stuhlgangs, deutlich über die Toleranzgrenze der Partei hinausgegangen sein.

Auch wenn viele der durch Li Zhisui beschriebenen historischen Einzelheiten berechtigterweise umstritten sind und viele von ihnen mangels Zugang zu entsprechenden historischen Dokumenten auch nicht nachgeprüft werden können, kann man nicht ignorieren, dass Veröffentlichungen wie diese dennoch von sehr hoher Relevanz für das kollektive Gedächtnis in China sind und darüber hinaus als politischer Akt verstanden werden sollten. Während wissenschaftliche Aufsätze oder Geschichtszeitungen in der Regel nur von einem sehr kleinen Fachpublikum gelesen werden, kann ein solches Buch - trotz Zensur - eine enorme Aufmerksamkeit erzeugen, was auch damit zusammenhängen dürfte, dass dessen Veröffentlichung mit dem Beginn des Erinnerungsbooms in China zusammenfiel.

562 Ebd., S. 234. 
Ich war Maos Leibarzt kann deshalb durchaus als eine starke „Waffe“ im Kampf um das kollektive Gedächtnis angesehen werden.

\subsubsection{Zhang Yihe - Vergangenes vergeht nicht wie Rauch}

Im Jahr 2004 erschien knapp zehn Jahre nach Ich war Maos Leibarzt mit Vergangenes vergeht nicht wie Rauch (wangshi bing bu ruyan 往事并不如烟) ein Buch, das das Schicksal der Intellektuellen während der Kampagnen Maos, insbesondere jedoch während der Kampagne gegen Rechtsabweichler, beleuchtet, und das in einem ähnlichen Maße den Ärger der KPCh und Aufmerksamkeit in der VR China auf sich zog wie die Memoiren des ehemaligen Leibarztes Maos. Es gab jedoch einen entscheidenden Unterschied zwischen diesen beiden Büchern: Das Buch der Autorin Zhang Yihe 章诒和 konnte für ein sehr kurzes Zeitfenster von wenigen Wochen zunächst auf staatlich legitimiertem Wege veröffentlicht und vertrieben werden, bevor es schließlich dann doch der Zensur durch die chinesischen Behörden zum Opfer fiel. Nachdem die erste Auflage bereits in Umlauf gebracht worden war und somit nicht mehr ohne Weiteres aus dem Verkehr gezogen werden konnte, blieb den Behörden nichts anderes übrig, als die Zensur in der Form anzuwenden, dass sie erst mit einem Verbot des Drucks einer weiteren Auflage praktisch in Kraft treten konnte. Dies ist durchaus ein bemerkenswerter Vorgang, da es ein Spiegelbild für die vermutlich existierende Uneinigkeit hoher Parteikader über die Grenzen des Sagbaren zu sein scheint. Immerhin war es die gleiche Behörde, die zunächst über die Genehmigung einer Veröffentlichung im Verlag Volksliteratur (Renmin wenxue chubanshe 人民文学出版社) entschieden hatte, die diese innerhalb kürzester Zeit, vermutlich jedoch durch andere Mitarbeiter, wieder revidierte, auch wenn sich mangels Akteneinsicht die genauen Vorgänge um diesen Entscheidungsprozess nur erahnen lassen. Dies zeigt ebenso, dass es auch zu jenem Zeitpunkt keine eindeutigen Regeln darüber gegeben haben dürfte, was zu schreiben erlaubt war und was nicht.

Hier sollte jedoch berücksichtigt werden, dass sich die veränderte Haltung der Zensurbehörde keineswegs nur auf den Inhalt des Buches zurückführen lassen kann, sondern in Zusammenhang mit dem politischen Agieren der Autorin und den damit im Zusammenhang stehenden Entwicklungen in den Wochen nach dem Erscheinen gesehen werden muss. Denn kurz danach forderte die Autorin, dass die KPCh sich für die „historischen Fehler“ der Kampagne gegen Rechtsabweichler und der Kulturrevolution öffentlich entschuldigen solle. Zudem wurde sie im gleichen Jahr mit dem Preis des chinesischen PEN-Zentrums ausgezeichnet, 
was wiederum ein unerwünschtes Maß an Aufmerksamkeit auf die „historischen Fehler“ der KPCh und die Menschenrechtsverletzungen in China lenkte. ${ }^{563} \mathrm{Im}$ Zuge der Preisverleihung kam es zur Verhaftung der bekannten chinesischen Schriftsteller Yu Jie, Liu Xiaobo und Zhang Zuhua, die dieser beigewohnt hatten. Das PEN-Zentrum prangerte dies als schwere Menschenrechtsverletzung an und erhielt auch öffentlichen Zuspruch der Preisträgerin Zhang Yihe. ${ }^{564}$

Als im Jahr 2007 dann schließlich all ihre Bücher verbannt wurden, unter anderem auch das Nachfolgewerk Vergangene Geschichten von Stars der Pekingoper (Original: lingren wangshi 伶人往事), verfasste sie einen öffentlichen Brief an die Regierung, in dem sie ein Ende der Zensur forderte und sich für die Meinungsfreiheit in China, insbesondere in Bezug auf die Fehler der Partei, einsetzte. Sie ging sogar noch einen Schritt weiter, indem sie schließlich die staatliche Zensurbehörde verklagte. Auch wenn die Klage natürlich überhaupt gar nicht erst angenommen und verhandelt wurde, erzeugte dies ein so großes Ausmaß an öffentlicher Aufmerksamkeit, dass die Partei sich dazu veranlasst sah, Zhang ein lebenslanges Veröffentlichungsverbot in China auszusprechen. Die zentrale Forderung nach einer Aufarbeitung politischer Fehler sollte sie auch in Zukunft dennoch häufiger wiederholen, zuletzt im Zuge des 60. Jahrestags des Beginns der Kampagne gegen Rechtsabweichler im Jahr 2017. Erneut forderte sie eine öffentliche Entschuldigung der Partei, eine angemessene Bewertung der Geschichte und das Schaffen von Erinnerungsorten für die Opfer politischer Kampagnen in der Volksrepublik, denn ohne diese, davon zeigte sie sich überzeugt, könne es keinen gesellschaftlichen Fortschritt geben. Zudem hält sie die Tatsache, dass das gegenwärtige Regime unter der Führung Xi Jinpings die Intellektuellen, ebenso wie in den 1950er Jahren, zum Schweigen gebracht habe, für einen schweren Rückschritt, der China eines Tages teuer zu stehen kommen werde. ${ }^{565}$

Im Vergleich zu Li Zhisuis Buch aus dem Jahr 1994 ist Die Vergangenheit vergeht nicht wie Rauch, ebenso wie die nachfolgenden Veröffentlichungen Zhang Yihes, also wohl nicht nur aufgrund besonders problematischer Darstellungen der „historischen Fehler“ der KPCh zensiert worden, sondern weil die Autorin das

563 Das unabhängige chinesische PEN-Zentrum ist eine im Jahr 2001 durch chinesische Exilschriftsteller gegründete Nichtregierungsorganisation, die sich für die Meinungsfreiheit einsetzt und Schriftseller in China unterstützt, die sich mit Themen beschäftigen, die die KPCh möglichst aus dem öffentlichen Diskurs heraushalten möchte. Siehe Independent Chinese PEN Center 2018, https://www.chinesepen.org/english/about-icpc.

564 Siems 2004, https://web.archive.org/web/20111220172016/http://www.pen.org/viewmedia. php/prmMID/135.

565 Lau 2017, https:/www.scmp.com/news/china/policies-politics/article/2084708/one-writersmission-call-chinas-communist-party-account. 
Schreiben mit einem Akt der unerwünschten politischen Partizipation verknüpfte. Doch trotz der Zensur hat nachfolgend analysiertes Buch eine hohe Relevanz für den Kampf um das kollektive Gedächtnis und die Neudeutung der Kampagne gegen Rechtsabweichler, da die Nachfrage auf dem chinesischen Schwarzmarkt wohl sehr groß gewesen ist. Während nur rund 300.000 Exemplare auf legalem Wege vertrieben werden konnten, sprechen verschiedene Quellen davon, dass sogar mehrere Millionen Exemplare auf diese Weise innerhalb Chinas verkauft worden sein sollen. ${ }^{566}$

Das zentrale Motiv des Buches lässt sich, wie das der meisten ihrer Nachfolgewerke auch, als Kampf gegen das Vergessen bezeichnen. Dies impliziert nicht nur der Titel des Buches, durch den die Autorin darauf hindeutet, dass die schmerzhafte Vergangenheit eben nicht einfach wie Rauch im Laufe der Zeit mit dem Wind davongetragen wird, sondern sie beschreibt auch im Vorwort der chinesischen Ausgabe ihre Intention, vorwiegend an die Intellektuellen, die der Kampagne gegen Rechtsabweichler, aber auch der Kulturrevolution zum Opfer gefallen sind, zu erinnern. Sie sieht es als ihre Aufgabe an, ihre eigenen Erinnerungen an die Vergangenheit festzuhalten, da Erinnerungen einen wichtigen Teil der Geschichtsschreibung darstellen:

Dieses Buch ist ein erinnerungswürdiger Teil meiner Vergangenheit, es stellt aber keine vollständigen Memoiren dar. Einst war die edelste und seltenste persönliche Tätigkeit das Erinnern. Denn sie ist der sicherere Weg, die Gesellschaft zu bewahren, als durch Tagebücher oder Briefe. Viele Menschen waren verletzt und verängstigt, haben alle privat geschriebenen Transkripte vernichtet und haben dann die wahren Erinnerungen an die Vergangenheit ausgelöscht. Das Ergebnis dessen war, dass die Geschichte nicht nur verwischt, sondern auch in einer unglaublichen Geschwindigkeit neu geschrieben worden ist. Diese Art der „Erinnerungen“ ist wie das Festhalten von Sand, er rinnt schnell durch die Finger. Die Leute von früher glaubten alles, sie glaubten ... und plötzlich glaubten sie gar nichts mehr. Warum ist das so? Ich befürchte, dass es durch die langfristige Umgehung und Ablehnung der Vergangenheit Probleme geben wird. ${ }^{567}$

Wie hier angedeutet wird, beruht das Buch auf ihren persönlichen Erfahrungen während der 1950er und 1960er Jahre. Auch wenn sie im Zuge der Kampagne nicht selbst zur Rechtsabweichlerin verurteilt worden ist - im Juni 1957 war sie auch erst 14 Jahre alt -, hat sie die Auswirkungen des Kampfes gegen die Intellektuellen in jenen Jahren dennoch persönlich zu spüren bekommen. Zhang Yihes Vater Zhang Bojun 章伯钧, damals stellvertretender Vorsitzender der politischen Konsulta-

566 Mooney 2004, http://www.worldsecuritynetwork.com/China-Asia/Mooney-Paul/GaggingChinas-intellectuals.

567 Eigene Übersetzung siehe Zhang 2004, S. 1. 
tivkonferenz des chinesischen Volkes und Verkehrsminister, wurde als „Rechtsabweichler Nummer 1“ aufgrund seiner Kritik an der KPCh zu einem der ersten und prominentesten Opfer der Kampagne, wenngleich ihm die Umerziehung durch Arbeit im Laogai-System letztendlich erspart geblieben ist. Während der Kulturrevolution wurde Zhang Yihe schließlich selbst aufgrund „konterrevolutionärer Verbrechen“ zum Opfer und verbrachte bis zu ihrer Freilassung im Jahr 1978 fast zehn Jahre zur Umerziehung durch Arbeit im Laogai-System.

Inhaltlich gliedert sich das Buch in fünf Teile, welche sich mit der Zeit vor, während und nach der Kampagne gegen Rechtsabweichler befassen. Jeder Teil stellt eine in sich geschlossene Erzählung aus dem Leben der Familie Zhang in jenen Jahren dar, welche auch ohne den jeweils vorangegangenen Teil gelesen und verstanden werden kann, jedoch beziehen sich die Erzählungen immer wieder aufeinander. Im Fokus jeder Erzählung steht neben ihrem Vater und ihrer Mutter stets ein sehr enger Kreis an Weggefährten der Eltern bzw. Einzelpersonen, die zur Zeit der Kampagne gegen Rechtsabweichler einen wichtigen Stellenwert für die Familie Zhang eingenommen haben und ebenfalls zu Opfern der politischen Entwicklungen jener Jahre geworden sind. Teil eins, Zwei Blätter vom Zufall zusammengeweht (liang pian luoye, ou'er chui zaiyiqi 两片落叶, 偶尔吹在一起) beschäftigt sich mit der Verurteilung des Vaters der Autorin und seines Weggefährten Chu Anping 储安平, damals Herausgeber der Zeitschrift Guangming Ribao 光明日报, als Rechtsabweichler; im zweiten Teil des Buches, Die Freundschaft eines Ehrenmannes (junzizhijiao 君子之交) erinnert sich die Autorin an die Freundschaft ihrer Eltern zu dem Künstler Zhang Boju 张伯驹 und seiner Frau; auch die dritte Geschichte, Der letzte Adel (zuihou de guizu 最后的贵族), handelt von Freundschaft, jedoch berichtet sie vorwiegend von der Zeit der Kulturrevolution und erinnert an die Begegnungen der Familie Zhang mit Kang Tongbi 康同 壁, der Tochter des berühmten Reformers Kang Youwei 康有为; die vierte Erzählung, Ein einsamer Mensch (siren jimo 斯人寂寞) berichtet von den späten Jahren des ebenfalls mit der Familie bekannten, sehr berühmten Schriftstellers Nie Gannu 聂绀㛎 und seinem Leben nach seiner Rehabilitierung; die fünfte Geschichte, Wie ein Berg zu sein (yi pian qingshan le ci shen一片青山了此身), befasst sich schließlich mit einem ehemaligen Rivalen des Vaters, Luo Longji 罗隆 基, damals Forstminister der VR China, und erzählt, wie dieser durch die Schicksalsgemeinschaft, die die beiden Politiker durch ihre Verurteilung als Rechtsabweichler miteinander bildeten, im Laufe der Jahre zu einem Freund der Familie geworden ist. Gegenstand der Erinnerungen der Autorin sind also vor allem Personen mit sehr hohen politischen oder gesellschaftlichen Positionen, womit sich das Buch auf ein ganz besonderes soziales Milieu der VR China der 1950er bis 1970er Jahre beschränkt. 
Insgesamt werden in Vergangenes vergeht nicht wie Rauch durch die Art, wie die Autorin die darin beschriebenen Weggefährten ihrer Familie beschreibt, wie in so vielen anderen Veröffentlichungen der inoffiziellen Geschichtsschreibung zur Kampagne gegen Rechtsabweichler, erneut alternative, immaterielle Erinnerungsorte zum Gedenken an die Opfer geschaffen. Die Autorin stützt sich in ihrer Darstellung der Vergangenheit neben ihren eigenen Erinnerungen vor allem auf die Erinnerungen des Vaters, die er vor seinem Tod im Jahre 1969 direkt mit seiner Tochter geteilt habe. Des Weiteren stützt sie sich auf die Erinnerungen der Mutter und die wiederum über die Mutter weitergegebenen Erinnerungen des Vaters. Dies betrifft vor allem die Jahre, die die Autorin im Laogai-System verbracht und deshalb nicht alle Vorgänge in ihrem Elternhaus persönlich mitbekommen hat. Hier zeigt sich erneut, weshalb solche Erinnerungen an die Vergangenheit als Teil der Geschichtsschreibung so problematisch sein können. Denn auch hier muss in Betracht gezogen werden, dass die Vergangenheit zum einen durch den zeitlichen Abstand, zum anderen aber auch durch die gefilterte, mehrfache Weitergabe der Erinnerungen bewusst oder unbewusst verzerrt worden sein könnte. Das bedeutet auch, dass es sich als äußerst schwierig darstellt, eine Unterscheidung vorzunehmen, was von dem Erzählten wahr ist, welche Erinnerungen durch die Jahre, die seit den beschriebenen Ereignissen vergangen sind, verzerrt wurden und welche durch künstlerische Mittel möglicherweise absichtlich verändert oder angepasst worden sind.

Doch wie stellt sich die Deutung der Kampagne gegen Rechtsabweichler durch Zhang Yihe nun konkret dar? ${ }^{568}$ Im Gegensatz zu vielen anderen Veröffentlichungen zu diesem historischen Ereignis ordnet sie die Ursachen, den Verlauf und die Folgen der Kampagne gegen Rechtsabweichler nicht in einen größeren historischen Zusammenhang ein, sondern bezieht sich zumeist nur auf ihre eigenen Beobachtungen und Wahrnehmungen sowie auf die der anderen ihr persönlich bekannten Erinnerungsträger. Sie verknüpft die Kampagne analytisch auch nicht mit der Kulturrevolution, wie es z. B. Hu Ping getan hat.

Das Buch weist aber Parallelen zu Berichten über den Vorabend der Kampagne auf. So berichtet Zhang Yihe, so wie auch der ehemalige Leibarzt Maos, dass die Euphorie für das neue China und der Glaube an die KPCh in den Kreisen ihres Vaters trotz der vorangegangenen Kampagnen gegen die Konterrevolutionäre oder gegen die Anhänger Hu Fengs durchaus sehr stark gewesen seien. Und so hätten weder ihr Vater noch sein damaliger Weggefährte Chu Anping, den er kurz zuvor als leitenden Redakteur für die Zeitschrift Guangming Ribao gewinnen

568 Die folgende Analyse bezieht sich auf die im Jahr 2008 im Verlag Zweitausendeins erschienene deutsche Ausgabe des Buches. 
konnte, an der Aufrichtigkeit der Berichtigungsbewegung und dem Aufruf zur Kritik im Zuge der Hundert-Blumen-Bewegung gezweifelt. Denn, da seien sie sich sicher gewesen, das neue China bräuchte Intellektuelle wie diese beiden Männer für den Aufbau des Sozialismus. Deshalb hätten sie auch keine Bedenken gehabt, Kritiksitzungen in den Räumlichkeiten der Zeitschrift zu organisieren und selbst Kritik und Verbesserungsvorschläge an die KPCh zu richten. Ihr Vater und sein Freund hätten nach Ansicht der Autorin in jenen Jahren zu naiv auf den Aufruf der Partei reagiert und deshalb zu deutliche Worte der Kritik fallen lassen. Genauer gesagt soll Chu Anping am 01. Juni 1957 unter anderem strukturelle Kritik an der Partei geäußert haben:

In den letzten Jahren klafften die Fähigkeiten vieler Parteimitglieder und die von ihnen übernommenen Aufgaben sehr weit auseinander. Dass sie ihre Arbeit zum Nachteil des Staates nicht gut machten und doch nicht überzeugt werden konnten, ihre Fehler zuzugeben, hat die Spannungen zwischen Partei und Massen verschärft, aber der Fehler liegt nicht bei diesen Parteimitgliedern, sondern bei der Partei, die ihre ungeeigneten Mitglieder in alle möglichen Positionen bringt. Wenn eine Partei das tut, entspricht das nicht der feudalistischen Denkweise à la L'état, c'est moi? Und das führt zu dieser Lage, wo unter dem Himmel alles monoton einförmig ist. Ich glaube, dieses „Parteienreich“, dieses ideologische Problem, ist die letzte Quelle für alle sektiererischen Phänomene. Hier liegt der grundlegende Widerspruch zwischen Partei und Parteilosen. ${ }^{569}$

Zhang Yihes Vater habe den Worten Chus, welche er später auch in der Zeitung veröffentlichte, noch während dieser Sitzung beigepflichtet. Daraufhin wurden beide wenige Monate später zu Rechtsabweichlern abgestempelt und in ihrem beruflichen Rang und Einkommen herabgestuft. Damit unterscheidet sich die Darstellung der Ereignisse der Tochter Zhang Bojuns rund um die Verurteilung von einem Großteil der Berichte anderer Rechtsabweichler bzw. ihrer Angehörigen, indem sie einräumt, dass ihr Vater und Chu durchaus deutliche Kritik an der Partei geäußert haben. Dies sollte deshalb aber keineswegs als Schuldeingeständnis interpretiert werden, denn die Autorin argumentiert, dass Chu und ihr Vater sich nur an die Vorgaben der Hundert-Blumen-Bewegung gehalten und sich somit nicht schuldig gemacht hätten, denn, davon ist Zhang überzeugt, die beiden seien in die durch Mao ab Mitte Mai gelegte Falle geraten. Sie erklärt die Bereitschaft der Intellektuellen, im Zuge der Hundert-Blumen-Bewegung ein so großes Risiko einzugehen, indem sie die Partei teilweise deutlich kritisierten, damit, dass sie dies sowohl aufgrund der durch die Partei entfachten Welle der Begeisterung als auch aufgrund einer Art Pflichtgefühl dem Staat gegenüber getan hätten:

569 Zhang 2008, S. 44. 
Kurz, ob nun Schlangen aus ihren Gruben krochen oder die Vögel selbst ins Netz gingen, sie waren in diesem Ausgenblick, in dem die Begeisterung so hoch schlug, dass man den Eindruck eines unkontrollierbaren Impulses bekam, verpflichtet, den Machthabern und der Gesellschaft ihr Denken zu erklären. Als Vater danach wieder zu sich kam, war er wegen Chu Anping voll schmerzlicher Reue und sagte von Gewissensbissen geplagt: „Der alte Philosoph Mengzi hat uns gewarnt: ,Regieren ist nicht schwer, nur ruf nie Unwillen hervor im Zimmer der Beamten!' Doch was der alte Chu herausgefordert hat, das ist die große Furcht des Kaisers. “570

In diesem Zusammenhang charakterisiert die Autorin die Bewegung gegen die Rechten eindeutig als „historischen Fehler“, indem sie darlegt, dass das, was nach der Falle folgte, die Kritiksitzungen und die falschen Anschuldigungen, Terror gewesen sei:

Unversehens hatte sie mit ihrer harten Rede die Aussagen Chu Anpings von einem juristischen Standpunkt aus kriminalisiert. Plötzlich wehte den Menschen ein scharfer Wind ins Gesicht und ein Unwetter braute sich über ihren Köpfen zusammen. Vor den Augen der Buchgelehrten schlug die Situation um, was folgte, war grausamer Terror. ${ }^{571}$

Die Beschreibungen der Folgen, die dieser Terror in Form der Verurteilung des Vaters für ihn selbst und die Familie hatte, weisen ebenfalls einige Unterschiede zu den Berichten vieler anderer ehemaliger Rechtsabweichler auf und zeigen, dass es eine sehr große Ungleichbehandlung der Verurteilten gegeben hat. Denn trotz der sehr deutlichen Kritik an der Partei durch den Vater und Chu Anping wurden beide nicht zur Umerziehung durch Arbeit verurteilt. Trotz der Herabstufung des beruflichen Ranges und des Gehaltes konnte Zhang Bojun mit seiner Familie in seinem luxuriösen Haus wohnen bleiben und sogar einen Teil des Personals behalten. Es ist der Familie Zhang zunächst also vergleichsweise gut gegangen. Als belastend habe die Familie der Autorin nicht die materielle, sondern vor allem die gesellschaftliche Herabstufung empfunden. Sie betont mehrfach, dass die Familie aus der Gesellschaft entfernt worden sei. Der Vater habe aufgrund dessen nach und nach die Lust verloren, sich sinnvollen Tätigkeiten zu widmen, wie etwa in die Forschung zu gehen oder sich mit Lyrik zu beschäftigen. Auch die Tochter habe die „Kälte der Mitmenschen“ gespürt und nicht verstanden, warum Rechtsabweichler so behandelt worden sind. Der Vater habe ihr damals erklärt, dass so etwas in westlichen Ländern nicht möglich wäre und dass dies ein Anzeichen dafür wäre, dass die Gesellschaft des neuen China unter der Führung der Kommunisten nicht besser sei als die alte unter der Guomindang: 
Das ist nur in China so. Xiaoyu, was weißt denn du? - Im Westen sind die rechten Parteien sehr angesehen und aktiv! Auf Versammlungen haben sie einen eigenen Vorsitzenden, der Unterschied zu den Linken besteht lediglich in ihren politischen Ansichten. Wenn über die Angelegenheiten des Staates diskutiert wird, sagt jeder seine Meinung, ob links, rechts oder Mitte, man trägt seine Ideen vor und erklärt seinen Standpunkt. Da die Standpunkte, Ideen und Vorstellungen der verschiedenen Gruppierungen unterschiedlich sind, muss es zwischen ihnen zwangsläufig zu lebhaftesten Debatten und Streitigkeiten, ja auch zu Angriffen kommen. Das alles sind ganz normale, legitime politische Erscheinungen. Die offizielle Politik der westlichen Länder muss sehr oft durch die Prüfung oder das Korrektiv solcher Debatten, Streitigkeiten und Angriffe hindurch. Der alte Mao hat bei uns jetzt die Rechten als antikommunistisch, volksfeindlich und antisozialistisch kriminalisiert und sie zur Klasse der Kapitalisten geschlagen. Auf diese Weise besteht zwischen der Linken und der Rechten kein ideologischer Unterschied mehr, sondern nur noch der politische Gegensatz von revolutionär zu konterrevolutionär. Wer in unserem Land einmal der politische Feind der Herrschenden geworden ist, oder als ideologischer Ketzer angesehen wird, dessen Tage werden schwer sein. Staat, Macht, öffentliche Meinung, Parteien, Gesellschaft, Freunde, sogar die Familie, alles rottet sich zusammen zu einer einzigen Kraft, die unentwegt auf diesen Feind und Ketzer einschlägt, ihn verfolgt und schließlich ausradiert. Früher habe ich einmal geglaubt, dass die neue Gesellschaft in dieser Frage besser wäre als die Guomindang. Jetzt sieht man, dass zu früher kein großer Unterschied besteht. ${ }^{572}$

Mit der Wiedergabe ihrer Erinnerung an die Aussage des Vaters in jenen Jahren, bezichtigt die Autorin die KPCh nicht nur der Unrechtsherrschaft, sondern stellt zudem auch einen deutlichen Bruch zum offiziellen Narrativ der Partei her, welches besagt, dass China durch den Sieg der Kommunisten über die Guomindang „aufgestanden“ sei. Die Aussage macht somit erneut deutlich, dass die Kampagne gegen Rechtsabweichler dazu führen konnte, dass viele Intellektuelle wie Zhang Bojun spätestens seit den Jahren 1957 und 1958 die Euphorie für das neue China verloren hatten.

Bemerkenswert an den Erinnerungen der Autorin an jene Jahre ist jedoch, dass sie in ihrem Buch beschreibt, dass die Verurteilung des Vaters, trotz der negativen gesellschaftlichen Folgen für ihre Familie, durchaus auch positive Aspekte gehabt habe. So berichtet sie, dass ihr positiv in Erinnerung geblieben sei, dass ihre Eltern nun mehr Zeit für ihre Tochter gehabt hätten, wodurch das Verhältnis zwischen ihnen herzlicher geworden sei. Wohl auch deshalb habe sie sich weder in jenen Jahren, noch während der Kulturrevolution von ihren Eltern losgesagt, wie es so viele andere Kinder von Rechtsabweichlern während jener politischen Turbulenzen taten. Besonders deutlich arbeitet die Autorin in ihrem Text jedoch die positiven Aspekte Kameradschaft, Freundschaft und Zusammenhalt heraus, die sie als Folge der Kampagne gegen Rechtsabweichler in ihrem Umfeld

572 Ebd., S. $94 \mathrm{f}$. 
sehr deutlich in Erinnerung hat. Auch wenn viele Mitmenschen sie und ihre Eltern fortan mieden, konnten sie dennoch eine Reihe von alten Freundschaften bewahren und sogar neue Freundschaften schließen. Nur wenige Monate nach der Verurteilung des Vaters schloss die Familie zum Beispiel eine enge Freundschaft zu dem aufgrund der Aufführung einer verbotenen Oper ebenfalls verurteilten Zhang Boju und seiner Frau, welche Zhang Yihe später in Malerei unterrichtete. Außerdem schlossen sie Freundschaft zur Familie Kang Tongbis, dem Schriftsteller Nie Gannu und sogar zu dem ehemaligen Rivalen des Vaters Luo Longji entwickelte sich aufgrund der Schicksalsgemeinschaft, die sie nun bildeten, ein freundschaftliches Verhältnis. Im Laufe der Zeit sei somit eine eigene, kleine verschworene Gemeinschaft von Rechtsabweichlern entstanden, in der man sich gegenseitig half und unterstützte. Die Familie Kang Tongbis unterstützte die Familie Zhang beispielsweise während der „drei schweren Jahre“ der Hungersnot in Folge des Großen Sprungs nach vorn immer wieder mit Lebensmittelmarken, von denen sie selbst anderen abgegeben hätten. Und nach dem Beginn der Kulturrevolution nahmen sie die Autorin aus Sicherheitsgründen für eine Zeit lang bei sich auf. Trotz des Leids, den die Kampagne gegen Rechtsabweichler für die Mitglieder dieser Gemeinschaft bedeutete, seien der Zusammenhalt und die gegenseitigen Besuche zu einem wichtigen Lebensinhalt für die betroffenen Familien geworden:

Wenn dieser Kreis von Rechtsabweichlern zusammenkam, ging es hoch her. Bei einer Tasse grünem Tee wurde geredet und gelacht. Luo Longji plauderte über internationale Politik; über Buddhismus und klassische Lyrik sprach Chen Mingshu; sowohl über gesellschaftliche Neuigkeiten wie über Kochen und Kunst ließ sich das Ehepaar Chen Mingde und Deng Jixing aus. Es war ein Geben und Nehmen, man kümmerte sich umeinander und man schätzte sich. War jemand krank, wurde diese Nachricht automatisch weitergegeben, so dass man sich per Telefon nach dem Befinden erkundigen oder einen persönlichen Besuch machen konnte. Da die meisten in diesen Tagen keine andere Beschäftigung hatten, waren die gegenseitigen Besuche ihr Lebensinhalt. Unter den isolierten und deprimierenden Verhältnissen waren diese Treffen Festtage..$^{573}$

Die Autorin erinnert durch ihre Beschreibungen der persönlichen Beziehungen ihrer Familie in besonderer Weise an die einzelnen Mitglieder der Gemeinschaft, von denen die meisten im Laufe der Zeit verstorben sind. Durch die Art der Erinnerung an jene Personen wird abermals deutlich, dass die Autorin mit ihrem Buch einen alternativen Erinnerungsort erschaffen hat und sich damit gegen das Vergessen der einstigen Weggefährten ihrer Familie einsetzt. Dies wird in besonderer Weise ersichtlich, als sie an Chu Anping erinnert, der zu Beginn der

573 Ebd., S. $181 \mathrm{f}$. 
Kulturrevolution verschwand und dessen Schicksal bis heute ungeklärt geblieben ist - Gerüchte besagen, dass er sich entweder das Leben genommen habe oder von Rotgardisten zu Tode geprügelt worden sei. In ihrer Abschlussbemerkung zum Schicksal Chu Anpings merkt sie deshalb an: „Chu Anping hat niemals seinen Frieden gefunden. Seine Auferstehung steht bevor.“574

Dies wird ebenso deutlich, als sie unterstreicht, dass ihr Vater und Zhang Boju Ehrenmänner gewesen seien, dass der Künstler ein Herz voller Menschlichkeit besessen habe und dass diese Ehrenmänner letztlich von der Revolution verschlungen worden seien. Mit ihrem Text bewahrt sie die Erinnerung an diesen wertvollen Charakter, Zhang Boju:

Ein gebildeter und unkonventioneller Kopf wie er war in einem Regime wie dem unseren etwas Erratisches, etwas aus einer anderen Zeit. Und doch muss das, was man an ihm erratisch und unzeitgemäß nennen mag, erst durch die Zeit hindurchgehen, um seine wahre Bedeutung erkennen zu können. Seine Zeit hat ihn aufgerieben, doch die Zeit wird ihn bewahren. Anders als andere, die zu ihrer Zeit Helden genannt werden und die in der Zeit untergehen. Zhang Boju hatte ein reiches und ein reines Leben. Mit seiner besonderen Geschichte lebte er vor, was es heißt, ein „Mensch“ zu sein, ein chinesischer Literat in Erscheinung und Gemüt. ${ }^{575}$

In diesem Zusammenhang prangert sie zudem die Tatsache an, dass es auch nach dem Beginn der Reform- und Öffnungspolitik nicht möglich gewesen ist, Gedenkstätten für die Opfer der Kampagne zu errichten, was auch die Witwe des Künstlers Zhang Boju erfolglos versucht habe.

In ähnlicher Weise erinnert sie auch an die Familie Kang, denn insbesondere Kang Tongbis besonderer Charakter habe ihr gesamtes späteres Leben beeinflusst:

Kang Tongbi mit ihrer reichen Erfahrung und Bildung setzte auch in ihren späten Jahren alles daran, sich ihre Menschenwürde und Freiheit zu bewahren. Ihr war klar, dass ein Leben ohne Willen zur Unabhängigkeit und ohne die Fähigkeit, sich selbst vorzustehen, sehr bitter und erniedrigend war. ${ }^{576}$

Aufgrund der Erlebnisse mit der Familie Kang setzt sie der Tochter des berühmten Reformers Kang Youwei, an den im Gegensatz zu seiner Tochter noch immer erinnert wird, in ihrem Text ein Denkmal:

574 Ebd., S. 90.

575 Ebd., S. $177 \mathrm{f}$.

576 Ebd., S. 253. 
Kang Youweis Grab ist in Qingdao. Während der „Kulturrevolution“ wurden seine Gebeine in alle Winde zerstreut. Die revolutionären Massen paradierten durch die Straßen und stellten seinen Schädel mit dem weißen Haar zur Schau. Wie es heißt, hat ein Friedhofswärter die sterblichen Überreste zusammengesammelt und wieder ins Grab gelegt. Verglichen mit ihrem Vater werden Mutter und Tochter Kang in Frieden in der Erde ruhen, niemand stört sie und niemand erinnert sich an sie. Heute, wo nichts mehr heilig und rein genannt werden kann, ist die ehemals verehrte Kang Tongbi der Vergessenheit anheimgefallen; dass ich ihr die gebührende Achtung erweisen und ihre Anwesenheit spüren darf, ist für mich eine große Freude. $^{577}$

Trotz des teilweise sehr deutlichen Fokus auf die positiven Erlebnisse, die ihrer Familie dank der menschlichen Begegnungen trotz der Kampagne gegen Rechtsabweichler in jenen Jahren widerfahren seien, beschreibt sie den Tod des Vaters im Jahr 1969 als Langzeitfolge der Kampagne gegen Rechtsabweichler:

Er wollte nicht mehr leben, das war letztlich der Grund für seinen Tod - samt einer auch für Nahestehende schwer zu begreifenden seelischen Verletztheit und geistigen Einsamkeit, von den Demütigungen, der Erschöpfung und Niedergeschlagenheit ganz zu schweigen. Das alles führte dazu, dass er entschlossen von dieser vertrackten Welt, von der er nichts mehr erwartete, Abschied nahm. „Leben“ war für Vater ein zu luxuriöses Wort geworden, er war innerlich voller Schmerz und Trauer, also ging er. ${ }^{578}$

Die politische Verantwortlichkeit für das durch die Kampagne gegen Rechtsabweichler verursachte Leid schreibt sie eindeutig Mao Zedong alleine zu. Schließlich sei es Mao gewesen, der die Falle höchstpersönlich gelegt habe. Dies sei einigen der Weggefährten des Vaters bereits damals klar gewesen. Luo Longji habe diese Frage bereits kurz nach seiner Verurteilung mit dem Vater der Autorin erörtert: „Ach, Bojun, diese Bewegung gegen Rechtsabweichler. Was hat Mao getan? Er hat uns zum Reden verleitet und uns zu Unrecht bezichtigt. Und wir sind durch Feuer und Eis gegangen. “579 Auffällig ist, dass sowohl der Vater der Autorin als auch viele seiner Weggefährten Mao damals immer wieder als „Fürst“ bezeichnet haben sollen. Damit vermittelt die Autorin das Bild, dass Mao als Alleinherrscher auch die alleinige Verantwortung für die „historischen Fehler“ jener Jahre zugeschrieben werden müsse. Die Autorin geht sogar noch weiter, indem sie beschreibt, wie ihr Vater und Luo Longji Mao aufgrund seiner Politik gegen die sogenannten Rechtsabweichler damals des Verfassungsbruchs bezichtigt hätten.

577 Ebd., S. 269.

578 Ebd., S. 260 f.

579 Ebd., S. 378. 
Die führende Rolle Deng Xiaopings während der Kampagne gegen Rechtsabweichler, die er als Generalsekretär der KPCh innegehabt hatte, bleibt durch die Autorin hingegen gänzlich unerwähnt. Jedoch lässt sie auch der Politik Deng Xiaopings im post-maoistischen China eine kritische Bewertung zukommen, indem sie der Partei die Fähigkeit zur Modernisierung abspricht und letztlich indirekt zu ihrem Sturz aufruft. Dies tut sie jedoch nicht selbst, sondern lässt in dieser sehr kritischen Betrachtung den 1986 verstorbenen Schriftsteller Nie Gannu zu Wort kommen, indem sie Auszüge aus einem Gespräch, welches sie vor seinem Tod mit ihm geführt habe, wiedergibt:

Fünfzig Jahre lang hat es sich die Kommunistische Partei zur Pflicht gemacht, die Welt zu verändern, aber was es wirklich zu verändern gälte, wäre zunächst einmal die Kommunistische Partei selbst. Ihre sämtlichen Fehler, Übeltaten und Schweinereien hat sie im Namen der Revolution und mit politisch „korrekter“ Haltung verbrochen. Die armen kleinen Leute! Ich bin kein Pessimist, aber ich bin verzweifelt. Bis heute habe ich in der Kommunistischen Partei keine Kraft gesehen, die in der Lage wäre, die Partei von innen heraus zu verändern. Jetzt ist viel von Modernisierung die Rede, und in der Tat, nach außen hin ist alles modern, aber im Innern herrscht immer noch der reine Feudalismus; der Autokratismus im System hat sich nicht geändert. Die oberen Schichten sind modern, die unteren sind Steinzeit, das einfache Volk ist immer noch bei Hacke und Büffel. Wenn sich das nicht von Grund auf ändert, wird nichts anderes übrig bleiben, als diese Kommunistische Partei zu stürzen und von vorn anzufangen. Vielleicht muss das nicht einmal jemand anderes tun. Einparteienherrschaft, ein bürokratisches System, Cliquen- und Vetternwirtschaft, Denkverbot, moralischer Verfall und Genusssucht, Jagd nach schnellem Erfolg, Großmannssucht, falsche und frisierte Erfolgsmeldungen, wenn das alles zusammenkommt, wird sich die Partei am Ende selbst stürzen; aber sie werden erst damit aufhören, wenn sie das Land ruiniert haben. ${ }^{580}$

Auch wenn Aussagen wie diese nicht im Fokus des Buches stehen und nur eine Randnotiz darstellen, agiert die Autorin mit dieser Aussage dennoch deutlich außerhalb der von der Partei vorgegebenen Grenzen des Sagbaren, indem sie die Herrschaftslegitimation der KPCh klar in Frage stellt. In seiner Gesamtheit stellt das Buch vor allen Dingen jedoch eine Herausforderung für das offizielle Narrativ zur Kampagne gegen Rechtsabweichler dar.

Schlussendlich lässt der Erfolg von Büchern wie Vergangenes vergeht nicht wie Rauch oder Ich war Maos Leibarzt die Frage aufkommen, ob die Zensur der KPCh nicht ein größeres Interesse und mediale Aufmerksamkeit auf diese Narrative gelenkt hat, als es ohne diese Maßnahme überhaupt der Fall gewesen wäre. Das Agieren der Behörden kann aus Sicht der KPCh durchaus ein zweischneidiges Schwert darstellen, denn einerseits kann eine Diffamierung der Machthaber der Vergangenheit einen negativen Einfluss auf die Herrschaftslegitimation der Partei

580 Ebd., S. 325 f. 
in der Gegenwart ausüben, andererseits muss in Betracht gezogen werden, dass die mediale Aufmerksamkeit, die durch das Veröffentlichungsverbot dieser Bücher oder bestimmter Geschichtszeitungen ausgelöst werden kann, möglicherweise erst recht eine Verstärkung des Diskurses um die „historischen Fehler“ der KPCh nach sich zieht.

\subsection{Die Geschichtszeitschrift Bashan Yeyu 巴山夜雨}

Das elektronische Journal Bashan Yeyu (wörtl. Nachtregen auf dem Berg Ba) wurde im Jahr 2010 von ehemaligen Rechtsabweichlern und ihren Kindern in Chongqing gegründet, also genau in der Zeit, in der die Vorbereitungen von Xi Jinpings Kampf gegen den historischen Nihilismus hinter den Kulissen bereits begannen. Zwischen 2010 und 2014 sind in unregelmäßigen Abständen insgesamt 27 Ausgaben des Journals erschienen. Vertrieben wurde es über ein E-MailAbonnement, zu dem sich Interessierte unter der E-Mail-Adresse bsyy1957@qq.com anmelden konnten. Die Herausgeber der Zeitschrift, die bis heute anonym geblieben sind, beschreiben im Vorwort der ersten Ausgabe ihre Intentionen für die Gründung der Zeitschrift. Demnach werde die Vergangenheit insbesondere dann relevant, wenn die Zeitzeugen alt werden. Und deshalb diene Bashan Yeyu der Wahrung der Vergangenheit und der Erinnerungen an sie:

Sie lässt die alten Freunde zum Reden zusammenkommen, nicht nur um verborgene historische Wahrheiten aufzuspüren und die Erinnerungen zu retten, die im Laufe der Jahre erodiert sind, sondern auch um den Austausch sowie das Sammeln von Informationen zu erleichtern und denjenigen, die die Erinnerungen aufschreiben, einen bequemen Weg zum Teilen dieser Erinnerungen zu ermöglichen; außerdem hilft sie den nachfolgenden Generationen, den Weg zu verstehen, den ihre Vorgänger gegangen sind. ${ }^{581}$

Im Zuge dessen rufen die Herausgeber die Leserschaft dazu auf, die Zeitschrift zu verbreiten. Dementsprechend sind alle Ausgaben auch über die Internetseite der PRC History Group verfügbar. ${ }^{582}$ Im Einklang damit lautet auch das Motto der Zeitschrift, welches über jeder Ausgabe erscheint: Erinnerungen retten (qiangjiu jiyi 抢救记忆), Wahrheit verfolgen (zhuixun zhenxiang 追寻真相), Informationen austauschen (jiaoliu xinxi 交流信息) und Daten sammeln (jilie ziliao 积累资料).

581 Eigene Übersetzung. Original siehe Bianzhe de hua 编者的话 (Worte der Herausgeber) 2010, S. 1.

582 Siehe The PRC History Group 2014, http://prchistory.org/night-rains-on-mount-ba/. 
Inhaltlich beschäftigt sich die Zeitschrift ausschließlich mit der Kampagne gegen Rechtsabweichler, wobei die in ihr abgedruckten Artikel sehr vielschichtig sind und Kurzmemoiren ehemaliger Rechtsabweichler oder Zeitzeugen, die von dem Schicksal von Freunden oder engen Angehörigen berichten, Gedichte, Statistische Angaben, wie z.B. Angaben zu Einzelfallkorrekturen in Chongqing mit entsprechenden Namenslisten, Tagebucheinträge, andere historische Aufzeichnungen, wie Briefe an die Behörden oder Aufzeichnungen von Reden, die die sogenannten Rechtsabweichler während der Hundert-Blumen-Bewegung gehalten hatten sowie Artikel, die auf narrativen Interviews beruhen oder makrohistorische Betrachtungen der Kampagne umfassen. Wie die Herausgeber bleibt ein Großteil der Autoren der Artikel bzw. der Kompilatoren der historischen Dokumente anonym. Zum Teil beinhaltet Bashan Yeyu jedoch auch Beiträge, die bereits in der Kategorie der durch die Partei tolerierten inoffiziellen Geschichtsschreibung veröffentlicht worden sind. In diesen Fällen werden auch die Autoren der Artikel genannt. Beispielsweise wurde sogleich als erster Artikel der ersten Ausgabe der in Kapitel 5 diskutierte Beitrag Guo Daohuis Die Wiederherstellung der Wahrheit ist der erste Schritt in Richtung Gerechtigkeit, welcher im Februar des Jahres 2010 in Yanhuang Chunqiu erschienen war, rund zwei Monate später in Bashan Yeyu abgedruckt. Dies unterstreicht nicht nur die Relevanz seiner darin getroffenen Analysen und Erkenntnisse, sondern zeigt auch, dass sich diese auch mit den Zielen des Journals Bashan Yeyu decken. Die neunte Ausgabe aus dem Jahr 2011 enthält die ebenfalls im vorherigen Kapitel diskutierte Erzählung Die Frau aus Shanghai von Yang Xianhui. Dies macht deutlich, dass die Grenzen zwischen zweiter und dritter Kategorie nicht immer klar definiert sind und dass die Kategorien vielmehr auch fließend ineinander übergehen können. Nicht alles, was innerhalb dieses politisch nicht legitimierten Journals veröffentlicht wird, ist politisch hochproblematisch und bewegt sich jenseits der Grenzen des Sagbaren. Bashan Yeyu beinhaltet vieles, was auch in den staatlich tolerierten Veröffentlichungen möglich gewesen wäre bzw. möglich ist. Dennoch gibt es einige gravierende Unterschiede, wie die folgende Analyse aufzeigen wird.

Wie bereits in Yanhuang Chunqiu spielen Kurzmemoiren eine entscheidende Rolle innerhalb des Journals und können auch hier als alternative Erinnerungsorte angesehen werden. In ihnen gedenken die Autorinnen und Autoren ebenfalls engen beruflichen Weggefährten oder Freunden, in erster Linie jedoch erinnern sie in ihnen an enge Familienmitglieder.

Wang Tongchu 王桐初 erinnert in ihrem Artikel Schwere Erinnerungen auf eben jene Weise an ihren Vater, der im Jahr 1957 als Rechtsabweichler verurteilt wurde und daraufhin ein Jahr später zur Umerziehung durch Arbeit nach Jiabiangou gekommen ist. Das ehemalige Umerziehungslager im Nordwesten Chinas, das bereits Gegenstand der durch die Partei tolerierten inoffiziellen Ge- 
schichtsschreibung gewesen war, wird durch die Autorin als „Massengrab“ (luan zang gang 乱葬岗) bezeichnet, in dem auch ihr Vater im Jahr 1961 unter ungeklärten Umständen den Tod gefunden habe. Zunächst berichtet sie über die Folgen, die die Familie erdulden musste, nachdem der Vater unschuldig, wie sie beteuert, verurteilt worden war. Die Verurteilung des Vaters sei nicht nur mit einem erheblichen gesellschaftlichen Abstieg, sondern auch mit einer Verarmung der Familie verbunden gewesen und ihr Großvater sei aufgrund der Trauer und Verzweiflung darüber wenige Monate nach der Verurteilung seines Sohnes verstorben. Darüber hinaus habe ihre Schwester als Tochter eines Rechten aufgrund ihres schlechten Klassenhintergrundes keine Zulassung zur Universität erhalten, obwohl sie die Eignungsprüfung bestanden hatte. Deshalb bezeichnet sie die Verurteilung des Vaters als Rechtsabweichler als Wendepunkt in ihrem Leben. Als sie die Nachricht über den Tod des Vaters erreichte, habe sie versucht, den Leichnam ihres Vaters nach Hause zu holen, doch die Behörden hätten ihr weder eine Auskunft über den Verbleib seiner sterblichen Überreste erteilt, noch hätten sie den Leichnam freigegeben. Als ihre Mutter im Jahr 1966 an einem bösartigen Tumor in der Wirbelsäule verstarb, konnten die Eheleute aufgrund dessen nicht nebeneinander begraben werden.

Auf die Schilderungen der Ereignisse, wie sie sich aus ihrer Sicht in jenen Jahren zugetragen haben, folgt ein Abschnitt, in dem die Intention der Autorin, durch den Text ihrem Vater zu gedenken, besonders deutlich wird. Unter einem Foto von ihm beschreibt sie zunächst seine positiven Charakterzüge:

\begin{abstract}
Das Wesen meines Vaters war ehrlich und freundlich. Er hasste Feindschaft, wollte Selbstachtung wahren, biederte sich nicht den einflussreichen Funktionären an und trat auch keiner Partei oder Organisation bei. In seinen Gedanken existierte das Konzept der Klasse nicht, für ihn zählte nur der jeweilige Charakter. Er verstand auch nicht die ungeschriebenen offiziellen Gesetze und auch nicht seine verkommene und korrupte Umgebung und deren vollkommene Unordnung, er hieß die Umstände nicht willkommen. Er wollte nur sein Bestes tun, um seine Expertise auszubauen und diese in einem auf Gleichheit beruhenden Umfeld ausüben. Dieser Charakterzug meines Vaters hat in der Vergangenheit dazu geführt, dass er $\mathrm{zu}$ einfachen Leuten, Mitgliedern des Explorationsteams und Arbeitern Freundschaften geschlossen hat. Er interagierte selten mit Politikern und auch wenn der Führer seiner Arbeitseinheit neben ihm wohnte, ergriff er kaum die Initiative. ${ }^{583}$
\end{abstract}

Nach der ausführlichen Hervorhebung seiner positiven Charaktereigenschaften betont sie erneut, dass der Vater unschuldig gewesen sei. Auch wenn er demnach gänzlich unpolitisch gewesen sei, sei er stets für die Partei und voller Liebe für China gewesen. Sie unterstreicht dies, indem sie darlegt, dass ihr Vater im Jahr

583 Eigene Übersetzung. Original siehe Wang 2011, S. 26. 
1949 die Möglichkeit gehabt habe, sein Heimatland zu verlassen und in die USA auszuwandern, was er aber abgelehnt habe: „Wenn man meinen Vater in Gänze betrachtet, komme ich nicht umhin, mich zu fragen: War er wirklich gegen die Partei und gegen das Volk?"584

Weiterhin wird durch diesen Text gegen das Vergessen deutlich, wie sehr diese Art der Geschichtsschreibung von einer quälenden Ungewissheit der Angehörigen über das wahre Schicksal der verstorbenen Rechtsabweichler geprägt sein kann. Wang legt dar, dass sie sich seit dem Jahr 1979 mit den Fragen quäle, warum ihr Vater überhaupt als Rechtsabweichler verurteilt worden war und welche Umstände zu seinem Tod geführt haben. Deshalb beantragte sie bei den zuständigen Behörden Akteneinsicht. Der für sie entscheidende Teil jedoch, das Protokoll der Kritiksitzung des Vaters im Jahr 1957, welches Aufschluss über die Vorwürfe gegen den Vater gegeben hätte, sei nach Angaben der Behörden während der Kulturrevolution verschwunden. Kritik an den Behörden übt die Autorin darüber hinaus auch, indem sie darlegt, dass die Kompensationszahlungen, die die Familie nach dem Jahr 1979 erhalten hatte, nicht ausreichend gewesen seien. Demnach habe die Familie nur 1.000 Yuan als Kompensation für den Verdienstausfall des Vaters während der Jahre 1958 bis zu seinem Tod im Jahre 1961 erhalten. Sie hält die Summe für diesen Zeitraum für viel zu niedrig. Vor allem aber wirft sie den Behörden vor, dass die wahre Todesursache des Vaters, welche in den Unterlagen als „natürlicher Tod“ angegeben werde, systematisch verschleiert worden sei, um nicht noch mehr zahlen zu müssen. Erneut zeigt sich, dass die Entscheidung der Regierung, die Opfer der Kampagne gegen Rechtsabweichler anders zu entschädigen als die Opfer der Kulturrevolution, auch die inoffizielle Geschichtsschreibung beeinflusst. Abschließend betont die Autorin noch einmal, dass sie sich nicht mit der Unwissenheit über das Schicksals des Vaters abfinden könne, und schließt ihren Beitrag mit einem Aufruf, in dem sie bittet, dass sich andere Rechtsabweichler, die mit ihrem Vater damals im Lager Jiabiangou gewesen sind und etwas über die Umstände seines Todes wissen, bei ihr melden sollen. ${ }^{585}$

Ein weiteres Beispiel eines solchen Textes gegen das Vergessen als alternativer Erinnerungsort stellt auch der Beitrag Song Xiaotaos 宋晓涛 dar, der an seinen im Jahr 1998 verstorbenen Vater Song Qingtao 宋清涛 erinnert, der ebenfalls unschuldig als Rechtsabweichler verurteilt worden war und aufgrund dessen rund 20 Jahre im Laogai-System verbringen musste. Seine Intention für die

584 Eigene Übersetzung. Original siehe ebd., S. 27.

585 Ebd., S. 29. 
Veröffentlichung des Textes, nämlich das Wahren der Erinnerung, macht der Autor gleich zu Beginn deutlich:

Ich möchte die Memoiren für meinen Vater schreiben, doch als ich tatsächlich den Stift in die Hand nehme, habe ich Probleme. Es ist nicht so, dass ich des Schreibens nicht mächtig wäre, aber es waren nicht einmal zehn Jahre, die ich gemeinsam mit meinem Vater verbracht hatte (1953 zog ich mit meinem Vater von Shanghai nach Chongqing, vom Osten in den Süden, und im Jahr 1960 wurde mein Vater drei Jahre lang zur Reform durch Arbeit fortgeschickt. 1964 schloss ich die Mittelschule ab und ging aufs Land und das ist 30 Jahre her) und es sind die Jahre während der Grund- und Mittelschule, an die ich mich nicht mehr erinnere, ich befürchte, dass die Erinnerungen an das Leben und die Erfahrungen meines Vaters unvollständig und ungenau sind. Ich habe einige Kinder gesehen, die die gleichen Erfahrungen wie ich gemacht haben, die gründliche Interviews mit Freunden geführt haben und die, nachdem sie alle Informationen gesammelt hatten, eine detaillierte Darstellung der Leben ihrer Väter hatten; ich bewundere das sehr, aber ich befürchte, dass ich dieses Niveau des Schreibens nicht erreichen kann. Später habe ich dann darüber nachgedacht, wenn die Erinnerungen unvollständig und ungenau sind, beschreibt man eine fragmentierte Realität auf dem Grabstein meines Vaters war die Phrase „die Realität ist die Kraft der Kunst“ eingraviert - und wenn dies wahr ist, tut es mir nicht leid, dass der Vater im Himmel ruht. ${ }^{586}$

Wie bereits Wang Tongchu beschreibt er zunächst, was die Verurteilung des Vaters als Rechtsabweichler für ihn selbst bzw. seine gesamte Familie in den darauffolgenden Jahren bedeutet habe. Auch er berichtet von sozialer Diskriminierung, von Armut und dass ihm der Zugang zu einer weiterführenden Schule verweigert worden sei.

Weiterhin schildert er, was es bedeutet habe, sich von der durch die Kampagne gegen Rechtsabweichler auferlegten Sippenhaft befreien zu müssen, um nicht von der Gesellschaft ausgeschlossen zu werden. Auf den Rat seiner Großmutter hin sagt er sich im Jahr 1964, wie so viele andere Kinder in jenen Jahren auch, von seinem Vater los. Dabei setzt er sich mit seinen eigenen Schuldgefühlen auseinander, die ihn aufgrund dessen fortan begleiten würden: „Ich fühle, dass ich meinen Vater verkauft habe, wie ein Verräter, der seine Seele verkauft, nur um seine eigene Zukunft zu schützen; ich bin schuldig!“587 Und obwohl er, wie er berichtet, schon damals von schweren Schuldgefühlen geplagt gewesen sei, sei sein Wunsch, an der Revolution ${ }^{588}$ teilzuhaben, letztlich stärker gewesen: ${ }^{58}$

586 Eigene Übersetzung. Original siehe Song 2011, S. 34.

587 Eigene Übersetzung. Original siehe ebd., S. 37.

588 Gemeint ist hier die von Mao Zedong 1958 formulierte Idee der permanenten Revolution, welche für die Jugendlichen insbesondere während der Kulturrevolution zur treibenden Kraft geworden ist. Siehe Cheek 2002. 
Der schwere politische Hut unterdrückte nicht nur Intellektuelle wie meinen Vater, er stach auch in die Herzen von uns „Kindern der fünf schwarzen Klassen“. Wir trugen die Sünden unserer Väter in uns und wir verpflichteten uns, unsere Kinder zu erziehen und ihre Seelen stets zu verdrehen. Nachdem ich 1964 aufs Land gegangen war, schwor ich, die „drei Bräuche“ zu durchschreiten und drei Jahre lang nicht nach Hause nach Chongqing zurückzukehren, um meine Entschlossenheit für die Revolution zu demonstrieren. ${ }^{590}$

Er resümiert, dass seine Familie, die einst sehr angesehen gewesen sei, durch die Kampagne gegen Rechtsabweichler nicht nur einen dramatischen gesellschaftlichen Abstieg erlebt habe, sondern auch auseinandergebrochen sei: „Die Vorfahren unserer Familie waren alle ruhmreiche Proletarier! Ein ,rechter` Hut hat einfach alles verändert."591

Auch dieser Text macht deutlich, dass die Ungewissheit über die Gründe der Verurteilung die Angehörigen der Rechtsabweichler lange umtreiben kann. Song sei bezüglich der Gründe für die Verurteilung seines Vaters lange Zeit im Dunkeln getappt, auch deshalb, weil dieser nicht mit seinem Sohn darüber sprechen wollte, was ihm in jenen Jahren widerfahren ist. Der Autor sei sich jedoch stets sicher gewesen, dass der Vater unschuldig gewesen sei, immerhin, so merkt er an, habe dieser während des Bürgerkriegs für die Kommunisten gekämpft. Auch Song kritisiert den Umgang der Behörden mit der Wahrheit deutlich. Wie auch Wang Tongchu habe er nach dem Tod des Vaters Akteneinsicht beantragt. Auch in diesem Fall sei ihm diese zunächst nicht gewährt worden. Letztlich habe er dennoch herausgefunden, weshalb sein Vater ein Rechtsabweichler geworden sei - im Jahr 1958 soll er öffentlich geäußert haben, dass Führungskräfte sich stetig fortbilden sollten, um Experten auf ihrem jeweiligen Gebiet zu werden, um so einen besseren Beitrag für die Entwicklung Chinas leisten zu können. Solche Aussagen galten damals als bourgeoises Gedankengut. Insgesamt habe diese Wahrheit Songs Einschätzung, dass sein Vater unschuldig gewesen sei und er nur aufgrund einer Ungerechtigkeit die besten Jahre seines Lebens verloren habe, nicht verändert.

Insgesamt verurteilt er die Kampagne gegen Rechtsabweichler deutlich. Er verbindet diese eindeutig kritische Haltung auch mit einer Kritik an der offiziellen

589 Der unbedingte Wille, an der „permanenten Revolution“ teilzuhaben, ist insbesondere von ehemaligen Rotgardisten ein immer wiederkehrendes Erklärungsmuster für das Lossagen von der Familie oder für die Gewaltexzesse, an denen sie während der Kulturrevolution beteiligt gewesen sind. Die Aufarbeitung der Schuld, die sie dadurch auf sich geladen haben, ist eine der zentralen Intentionen für die spätere Veröffentlichung von Memoiren durch ehemalige Rotgardisten. Siehe zum Beispiel Liu 2014.

590 Eigene Übersetzung. Original siehe Song 2011, S. 38.

591 Eigene Übersetzung. Original siehe ebd., S. 38. 
Geschichtsschreibung durch die Partei. Gleichzeitig verknüpft er sie mit der Hoffnung, dass sie nicht dauerhaft von Bestand wäre und dass sich aus gesellschaftlichen Fortschritten auch Fortschritte hinsichtlich der historischen Bewertung der Ereignisse der Jahre 1957 und 1958 und ihren Folgen ergeben würden:

\begin{abstract}
Mein Vater hatte Pech, und dennoch hatte er Glück im Unglück, da er sein Leben in diesem Desaster nicht verloren hat. Später wollte ich wissen, ob es unter den 500.000 Rechtsabweichlern viele Todesfälle gegeben hat. Jetzt sagen die Leute, dass alle, die Äußerungen gegen die Partei und gegen den Sozialismus getätigt haben, Rechtsabweichler gewesen seien und dass sie mit dem Aufsetzen des Hutes ihrer Bürgerrechte beraubt worden seien und das Mittel der Diktatur der Massen eingesetzt worden sei, um sie zu kontrollieren und zu verfolgen; dies hat Millionen von Menschen ihre Würde geraubt und sie seelisch und körperlich kaputtgemacht, weshalb viele von ihnen gestorben sind. Wir, die wir an der Geschichte teilgehabt haben, können das nachempfinden. Auch wenn die gegenwärtige Parteigeschichte noch immer darauf beharrt, dass „die Kampagne gegen Rechtsabweichler an sich richtig war, jedoch später übertrieben worden ist“, glaube ich, dass die Gesellschaft sich stets weiterentwickelt und dass mit einer Vertiefung der Demokratisierung der Tag kommen wird, an dem sie vollständig verdammt wird..$^{592}$
\end{abstract}

Damit stellt sein Text nicht nur eine offene Herausforderung der offiziellen Geschichtsschreibung dar, sondern er tritt damit gewissermaßen direkt in den Kampf um das kollektive Gedächtnis ein.

Wie diese beiden Beiträge bereits angedeutet haben, bedeutete die Kampagne gegen Rechtsabweichler häufig das Auseinanderbrechen der Familien. Die Aufarbeitung familiärer Traumata stellt neben dem Schreiben gegen das Vergessen ein weiteres zentrales Motiv einiger Beiträge in Bashan Yeyu dar.

In dem Artikel Im Jahr 1958 zerfällt eine Familie in drei Einzelteile (Yi jiu wu ba nian, san kou ren zhi jia yifen wie san 一九五八年, 三口人之家一分为三), der auf einem narrativen Interview mit einem Ehepaar beruht, wird dies in besonderem Maße deutlich. Zhu Peide 朱培德 und seine Ehefrau Zhao Ruizhu 赵瑞珠 berichten davon, dass, nachdem er $1957 \mathrm{zu}$ Unrecht, wie sie beide beteuern, als Rechtsabweichler verurteilt worden war, die Behörden sie dazu drängen wollen, sich von ihrem Mann scheiden zu lassen. Als sie dies verweigert, wird sie aufgrund dessen im Jahr 1958 schließlich selbst zur Rechtsabweichlerin und zur Umerziehung durch Arbeit verurteilt. Ihr Mann ist bereits seit mehreren Monaten in einem Umerziehungslager am Rande der Stadt Chongqing 重庆, sie selbst wird jedoch in den davon recht weit entfernten Landkreis Tongjiang 通江 in der Provinz Sichuan 四川 geschickt. Ihre zu diesem Zeitpunkt nur sechs Monate alte Tochter muss sie deshalb in die Obhut ihrer Schwiegermutter in Shanghai geben. Die Familie ist

592 Eigene Übersetzung. Original siehe ebd., S. 39. 
somit im ganzen Land, an drei unterschiedliche Orte verstreut. Zhao gibt zu Protokoll, dass ihr dies fast das Herz zerbrochen und sie sich unaufhörlich gefragt habe, was sie denn falsch gemacht habe. Nach vier Jahren gelingt es ihr schließlich, erfolgreich einen Antrag auf Versetzung zu ihrem Mann zu stellen, und die Eheleute können nach vier langen Jahren ihre Tochter wieder zu sich holen und unter erleichterten Haftbedingungen einem unter diesen Umständen recht normalen Familienleben nachgehen. Doch das Trauma, das diese Trennung verursacht habe, sei ein ganzes Leben lang geblieben. ${ }^{593}$

Die kritischen Berichte über die Versuche der Behörden, Ehepartner durch Druck dazu zu bewegen, sich von ihren rechtsabweichlerischen Männern respektive Frauen zu trennen, nehmen einen wichtigen Stellenwert in der Aufarbeitung der Kampagne ein. Insbesondere die Berichte derjenigen, die als Rechtsabweichler das Auseinanderbrechen der Familien „verursacht“ haben, zeigen, dass sie, auch wenn sie unschuldig gewesen sind, aufgrund dessen häufig lebenslang eine große Schuld mit sich tragen. Dies zeigt auch ein Beitrag über ein Ehepaar, das ebenfalls nacheinander als Rechtsabweichler verurteilt worden war, was ebenfalls eine Trennung von der kleinen Tochter verursacht hat. Während ihrer Umerziehung durch Arbeit sterben zunächst nicht nur die Eltern der Ehefrau Yang Heyu 杨和钰, sondern auch ihre Tochter verstirbt im Jahr 1961 an den Folgen der Großen Chinesischen Hungersnot. Von dieser Schuld habe sie sich ebenfalls ein Leben lang nicht lösen können, wie sie im Interview zu Protokoll gibt:

\footnotetext{
Meine Mutter starb im Jahr 1959, mein Vater im Jahr 1960 und meine vierjährige Tochter verhungerte im Jahr 1961. Sie alle starben verzweifelt. Heute sagen viele Leute „Yang Heyu hat ein gutes Leben“, aber mein Herz ist erfüllt von Schmerz; ich konnte weder meine kindliche Pietät und meine Verantwortung meinen Eltern gegenüber erfüllen, noch habe ich die Verantwortung für die Pflege meiner Tochter übernommen. ${ }^{594}$
}

Häufig sind die Darstellungen dieser Form des behördlichen Drucks auch mit einer generellen Kritik an der KPCh verbunden. Der ehemalige Rechtsabweichler Zhu Enyuan 朱恩源, nach eigenen Angaben seit Ende der 1930er Jahre treuer Kommunist, berichtet zum Beispiel davon, dass er 1957 nur aufgrund einer kritischen Äußerung seinem Vorgesetzten gegenüber als Rechtsabweichler zur Umerziehung durch Arbeit verurteilt worden sei. Dies habe zur Folge gehabt, dass seine Frau ebenfalls dazu gedrängt worden sei, sich von ihm scheiden zu lassen. Da sie dies verweigert habe und dann selbst zur Rechtsabweichlerin verurteilt worden sei, hätten ihre fünf Kinder einige Jahre ohne ihre Eltern aufwachsen

593 Zhu und Zhao 2010, S. $34 \mathrm{f}$.

594 Eigene Übersetzung. Original siehe Yang und Sun 2010, S. 38 f. 
müssen. Er selbst sei erst im Jahr 1979 rehabilitiert worden. In dem Interview aus dem Jahr 2001, auf den sich dieser Artikel bezieht, verbindet er seine Kritik an der Kampagne gegen Rechtsabweichler damit, dass er kritisch anmerkt, dass die KPCh der Gegenwart nichts mehr mit den Idealen gemein habe, die sie noch in den 1930er Jahren vermittelt habe:

\begin{abstract}
Auf der Antijapanischen Volksuniversität für Militär und Politik Chinas ${ }^{595}$ besagte die Lehre, dass es in einer kommunistischen Gesellschaft keine Ausbeutung und keine Unterdrückung gibt und die Werktätigen die Herren des Landes sind. Ich unterstütze diesen Punkt noch immer, jedoch sieht diese Theorie der Kommunistischen Partei in der Praxis ganz anders aus. Beispielsweise ist es so, dass ich, als ich in Yan'an studierte, lernte, dass die Kommunistische Partei eine Partei ist, die sich der hart arbeitenden Masse widmet. Es scheint in der Tat jedoch im Gegenteil so, dass sie sich um ihre eigenen Interessen kümmert und dass sich die Beamten mit ganzem Herzen ihrem eigenen Glück widmen; das widerspricht dem, was ich gelernt habe, völlig. Auf der Antijapanischen Volksuniversität für Militär und Politik Chinas wurde gelehrt, dass die Kommunistische Partei Ausbeutung und Unterdrückung beseitigt, Gleichheit für alle schafft. Das hat mich sehr ermutigt. Der Vorsitzende Mao hielt eine Rede und man fühlte, dass er den Menschen sehr nah war und sie absolut gleich waren. Jetzt, da die Kommunistische Partei seit einem halben Jahrhundert an der Macht ist, hat sie weder Ausbeutung und Unterdrückung beseitigt, noch hat sie Gleichheit für alle geschaffen. ${ }^{596}$
\end{abstract}

Hier zeigt sich, inwiefern die Berichte in dieser Kategorie der Geschichtsschreibung über den von der Partei noch tolerierten Rahmen hinausgehen können. Indem Zhu sagt, dass die KPCh weit von ihren ursprünglichen Idealen abgerückt sei, und er weiterhin ausführt, dass sie Ausbeutung und Unterdrückung fördere, kann man dies als ein Infragestellen der Herrschaftslegitimation der Partei interpretieren. Zhu geht sogar noch weiter, indem er sich kritisch über das chaotische Stadtmanagement seiner Heimatstadt Chongqing äußert:

Im Vergleich dazu bin ich der Meinung, dass das Stadtmanagement und die Polizei der Guomindang nicht so schlecht waren, wie sie es jetzt sind: Kurz gesagt, ich denke, dass gewisse Dinge in China schwierig umzusetzen sind, weil seine Wurzeln verfault sind. ${ }^{597}$

595 Die Antijapanische Volksuniversität für Militär und Politik Chinas (Zhongguo Renmin Kangri Junzheng Daxue中国人民抗日军政大学) wurde im Jahr 1931 als Universität der Roten Armee (Zhongguo Hongjun Daxue中国红军大学) durch die KPCh in Ruijin 瑞金 gegründet. Im Jahr 1937 erfolgte der Umzug nach Yan'an 延安, dem damaligen Hauptquartier der Kommunisten. 1945 wurde sie wieder aufgelöst. Siehe Sun 2015, http://www.mod.gov.cn/hist/2015-06/21/content_ 4591076.htm.

596 Eigene Übersetzung. Original siehe Zhu und Tan 2011, S. 46.

597 Eigene Übersetzung. Original siehe ebd., S. 46 
Indem er die Guomindang über die KPCh stellt, und sei es nur in dem Bereich des Stadtmanagements, geht er eindeutig über die Grenzen des Sagbaren hinaus. Hier zeigt sich erneut, weshalb die Zeitschrift nicht über einen von der Partei legitimierten Weg hätte vertrieben werden können.

Doch nicht alle Beiträge in Bashan Yeyu bewegen sich zwingend außerhalb dieser Grenzen. Beispielsweise gibt es eine Reihe von Artikeln, die auf einer romantischen Darstellung von Liebesbeziehungen in den Wirren der Kampagne gegen Rechtsabweichler beruhen. In ihnen steht das Überdauern der Liebe trotz aller politischen und gesellschaftlichen Widrigkeiten, denen die Rechtsabweichler ausgesetzt waren, im Fokus. Zwar schlagen auch diese Beiträge mitunter kritische Töne an, jedoch steht die Liebesgeschichte im Fokus und sie stellen in der Regel keinen Angriff auf die Herrschaftslegitimation der KPCh dar.

So berichtet etwa der ehemalige Rechtsabweichler Li Wenshu 李文书, wie seine große Liebe die Folgen seiner Verurteilung überstand. Nachdem er aufgrund einer karikaturistischen Zeichnung, die die Korruption hoher Beamter anprangerte, im Jahr 1957 im Alter von 21 Jahren zur Umerziehung durch Arbeit verurteilt worden war, schreibt er einen Brief an alle seine Angehörigen, in dem er sie dazu aufruft, sich vollständig von ihm loszusagen, um keinen Schaden von seiner Verurteilung davonzutragen. Daraufhin erhält er einen Liebesbrief von seiner Freundin. In diesem beteuert sie, trotz seiner Verurteilung an seiner Seite bleiben zu wollen. Li berichtet, dass ihn das motiviert habe, hart $\mathrm{zu}$ arbeiten und seine Transformation schneller zu durchlaufen. In diesem Zusammenhang kritisiert er Mao und berichtet von den schlechten Lebensbedingungen, insbesondere nach dem Ausbruch der Großen Hungersnot:

Aus historischen Fakten geht jedoch hervor, dass Mao Zedong diesmal die Menschen zum Narren gehalten, Unschuldige betrogen und Tricks angewendet hat. Nachdem ich den Hut des Rechtsabweichlers bekam, schien nichts mehr unmöglich zu sein; einige Tage nach der Verurteilung erhielt ich das größte „Geschenk“ und konnte den ersten Tagen der Hungerkatastrophe entkommen. Als der elfte Jahrestag der Gründung der VR näher rückte, konnte die Kantine keine Nahrung mehr zubereiten, die das Leben aller gesichert hätte, deshalb wurde die Hirse nicht mehr geschält, sondern gemahlen und in weißen Rettichblättern gekocht. ${ }^{598}$

Der Fokus seiner Schilderungen liegt jedoch auf dem Überdauern der Liebe bis zur Korrektur seines Urteils im Jahr 1979, als er seine große Liebe heiratet. Insgesamt verzichtet er darauf, die KPCh in Gänze in Frage zu stellen.

Ganz ähnlich stellt es sich in dem Artikel des Ingenieurs Zhu Liang 祝亮 dar, der, kurz nachdem er eine Romanze mit der Krankenschwester Liang Qian 亮俵

598 Eigene Übersetzung. Original siehe Li 2011, S. 35. 
begonnen hatte, aufgrund einer Kritik an seinem Vorgesetzten zum Rechtsabweichler verurteilt worden war. Der Autor des Artikels, welcher auf einem narrativen Interview mit den beiden Akteuren beruht, berichtet, dass sie beide zu Protokoll gegeben hätten, dass es sich um Liebe auf den ersten Blick gehandelt habe, und eine Trennung für Liang Qian auch nach der Verurteilung Zhu Liangs nicht in Frage gekommen sei. Auch in dieser Geschichte werden die historischen Ereignisse der VR China nach den 1950er Jahren kritisch beäugt und der Kampagne gegen Rechtsabweichler wird eine Schlüsselrolle für das Ausbrechen nachfolgender „historischer Fehler“ zugesprochen:

Mit Beginn der Kampagne gegen Rechtsabweichler war die gesamte chinesische Nation mit der Situation konfrontiert, dass es keiner mehr wagte, offen zu sprechen und sich alle schämten. Infolgedessen konnten der Große Sprung nach vorn, die Volkskommunenbewegung und die berüchtigte Kulturrevolution Mitte der 1960er Jahre ungehindert und reibungslos vonstattengehen, was für das Land und die Menschen große und irreparable Schäden hervorgerufen hat! ${ }^{599}$

Doch auch in dieser Geschichte sollte die Kritik an der Partei nur eine Randnotiz bleiben und die Darstellung der Liebesgeschichte im Fokus des Artikels stehen. Der Autor legt dar, dass, nachdem Zhu Liang zur Umerziehung durch Arbeit in ein weit abgelegenes Bergdorf geschickt worden sei, Liang Qian ihre Stelle aufgegeben und sich in eben jenes Bergdorf habe versetzen lassen, um bei ihrem Geliebten zu sein.

Ein nicht unerheblicher Teil der Beiträge in Bashan Yeyu geht jedoch eindeutig über die von der Partei tolerierten Grenzen hinaus. Dies zeigt sich insbesondere an den Artikeln, in denen die Autoren Kritik am offiziellen Umgang mit der Kampagne gegen Rechtsabweichler formulieren und damit einhergehend eine Neudeutung der Geschichte anstreben. Dies ist eines der zentralen Motive der Beiträge in dieser Zeitschrift.

Dabei stellt die aus Sicht der Autoren von der KPCh stark verfälschte Opferzahl einer der zentralen Kritikpunkte dar. Eine Reihe von Autoren vertritt die Meinung, dass die offizielle Zahl von 550.000 Rechtsabweichlern stark untertrieben sei. Viele von ihnen stützen sich auf ganz andere Erhebungen und Schätzungen. Es lässt sich interessanterweise eine Einigkeit unter den Autoren erkennen, dass die tatsächliche Zahl der zu Unrecht als Rechtsabweichler Verurteilten 3.178.470 betragen müsse. ${ }^{600}$ Yan Guixun 间桂勋 weist in diesem Zusammenhang darauf hin, dass man nicht vergessen dürfe, dass nicht nur die

599 Eigene Übersetzung. Original siehe Ma 2011, S. 23.

600 Siehe Yan 2013; Anonym 2013a, 2012. 
Rechtsabweichler selbst zu den Opfern gezählt werden müssten, sondern man darüber hinaus eigentlich auch die „,indirekten“ Opfer der Kampagne, nämlich die Angehörigen der Rechtsabweichler, zu den Opfern zählen müsse. Faktisch erhöhe sich die Zahl der Opfer dadurch dramatisch. Damit setzt er das, was in den bereits analysierten Kurzmemoiren immer wieder thematisiert wird, in einen größeren historischen Zusammenhang. Seiner Meinung nach verharmlose die bis in die Gegenwart gültige offizielle Opferzahl der Kampagne gegen Rechtsabweichler die historischen Tatsachen:

Ich habe das Gefühl, dass die Geschichte absichtlich verwässert wird, man es nicht wagt, die historischen Fakten zu benennen und dass man beabsichtigt, die Menschen die Geschichte absichtlich vergessen zu lassen, um die Verbrechen und die Schuldigen dieser „großen Verbrechen“ zu vertuschen. ${ }^{601}$

Yans Ausführungen implizieren somit eine deutliche Kritik an der KPCh. Er geht sogar noch weiter, indem er in diesem Zusammenhang sagt: „Es scheint, dass das Zeitalter des Lügens noch nicht vorbei ist und die Lügner noch immer Lügen erzählen. “602

Die Artikel weisen jedoch nicht nur eine Kritik an den statistischen Angaben der Kampagne auf, sondern auch an der offiziellen Deutung der Kampagne in der Resolution des Jahres 1981 und somit auch daran, dass sie, im Gegensatz zur Kulturrevolution, von der KPCh nicht als „historischer Fehler“ eingeordnet worden ist. Kritisiert wird hier, dass die KPCh noch immer an der Einschätzung festhält, dass die Kampagne, obwohl sie in ihrem Ausmaß übertrieben wurde, korrekt und notwendig gewesen sei. Die Autoren der Artikel ordnen die Kampagne gegen Rechtsabweichler, ähnlich wie die Akteure der von der KPCh tolerierten inoffiziellen Geschichtsschreibung, eindeutig als „historischen Fehler“ ein und formulieren mehrfach, dass sie dies auch von der KPCh einfordern. Auch hier zeigt sich, welch hoher Stellenwert die Einordnung der Kampagne gegen Rechtsabweichler als „historischer Fehler“ durch die Partei für die Opfer und ihre Angehörigen respektive für die Akteure dieser Kategorie der Geschichtsschreibung haben kann. Somit wird abermals deutlich, dass die Kategorie „historischer Fehler“ für die Opfer keine Verharmlosung eines historischen Unrechts darstellt, sondern als erster wichtiger Schritt für die Anerkennung des ihnen zugefügten Leids angesehen werden kann.

Einer der Autoren, dessen Name nicht genannt wird, erörtert, dass die Kampagne gegen Rechtsabweichler ein „historischer Fehler“ und somit ein Verbre-

601 Eigene Übersetzung. Original siehe Yan 2013, S. 2.

602 Eigene Übersetzung. Original siehe ebd., S. 3. 
chen gewesen sei. Insbesondere die am 01. August 1957 verabschiedete Direktive Entscheidung zum Thema Umerziehung durch Arbeit (Guanyu laodong jiaoyang wenti de jueding 关于劳动教养问题的决定), die der Umerziehung der Rechtsabweichler im Laogai-System einen juristischen Rahmen geben sollte, habe demnach sogar gegen die Verfassung des Jahres 1954 verstoßen. Denn der Beschluss besagte, dass dieser insbesondere dann in Kraft tritt, wenn eine Person gegen Artikel 100 der Verfassung verstoßen habe. Dieser lautet: „Die Bürger der Volksrepublik China müssen sich an die Verfassung und das Gesetz halten, Arbeitsdisziplin und öffentliche Ordnung wahren und die moralischen Verpflichtungen der Gesellschaft gegenüber achten." ${ }^{603}$ Der Autor verweist darauf, dass genau dagegen nachweislich so gut wie keiner der sogenannten Rechtsabweichler verstoßen habe: „Welcher Rechtsabweichler hat also gegen die Verfassung und das Gesetz verstoßen? Welcher Rechte hielt sich nicht an die Arbeitsdisziplin? Welcher Rechte wahrte nicht die öffentliche Ordnung? Welcher Rechte widersprach der sozialen Moral?“604 Genau deshalb stelle eine Verurteilung aufgrund eines angeblichen Verstoßes gegen Artikel 100 der Verfassung einen Verfassungsbruch dar. Der anonyme Autor legt weiterhin dar, dass die Partei durch die systematische Verfolgung der sogenannten Rechtsabweichler darüber hinaus auch gegen Artikel 89 der damaligen Verfassung verstoßen habe. Dieser besagt: „Die Freiheit der Person der Bürger der Volksrepublik China ist unverletzlich. Kein Bürger darf ohne Beschluss des Volksgerichts oder Genehmigung einer VolksStaatsanwaltschaft verhaftet werden." ${ }^{605}$ Er belegt dies damit, dass es für die Verurteilung zur Umerziehung durch Arbeit in jenen Jahren keines ordentlichen Gerichtsbeschlusses mit einer entsprechenden Beweisaufnahme mehr bedurfte. Der KPCh Verfassungsbruch vorzuwerfen, geht definitiv über die Grenzen dessen hinaus, was die Partei auch rund 60 Jahre nach dem Beginn der Kampagne toleriert. Dieser Tenor wiederholt sich jedoch in einer Reihe weiterer Artikel.

Auch Yan Guixin weist mit seinen statistischen Erhebungen darauf hin, dass, selbst wenn man die sehr vage gehaltenen Definitionen und Richtlinien des Jahres 1957 berücksichtige und sie für die Partei wohlwollend auslege, pro „echtem“ Rechtsabweichler noch immer 30.000 Unschuldige der Kampagne zum Opfer gefallen seien. Da dies in keinem Verhältnis stehe, könne die KPCh auch nicht daran festhalten, dass die Kampagne „korrekt und notwendig“ gewesen sei. ${ }^{606}$ In

603 Siehe Verfassung der Volksrepublik China (Erste Mao-Verfassung) vom 20. September 1954, Art. 100.

604 Eigene Übersetzung. Original siehe Anonym 2013b, S. 27.

605 Verfassung der Volksrepublik China (Erste Mao-Verfassung) vom 20. September 1954, Art. 89. 606 Yan 2013, S. 3. 
ihrer analytischen Bewertung stellen die Autoren somit das Narrativ der Resolution von 1981 erneut offen in Frage.

In ihrer historischen Bewertung der Rollen Mao Zedongs und Deng Xiaopings in der Kampagne schreibt die Mehrheit der Autoren vor allem Mao Zedong die Hauptverantwortung für die Umsetzung der Verbrechen der Jahre 1957 und 1958 zu. Gao Yuenong 高越农 vertritt zum Beispiel die Ansicht, dass die Kampagne gegen Rechtsabweichler eine von Mao akribisch geplante List zur Unterdrückung der Massen gewesen sei:

\begin{abstract}
Die Kampagne gegen Rechtsabweichler wurde von Mao Zedong geplant, um an dem dekadenten gesellschaftlichen System der Ein-Parteien-Diktatur festzuhalten, welches in Osteuropa zuvor herausgefordert worden war, mit dem Ziel, ,die Schlangen aus ihren Löchern zu holen“ und der Diktatur der Massen zu folgen; sie stellte eine Bewegung dar, die die nationalen, intellektuellen Vorreiter umkreiste und auslöschte. Sie war ein Wendepunkt für das Neue China und leitete den Übergang von einer demokratischen Republik zu einer autoritären Diktatur ein. Dies hat den guten Ruf der Kommunistischen Partei geschädigt und hisste die „dreiseitige rote Flagge“, die tausende von Menschen verhungern ließ. Und deshalb ist die Kampagne gegen Rechtsabweichler, von der Perspektive der historischen Charakterisierung, des Zwecks, der Mittel, der Inhalte und der Konsequenzen, von der Planung bis zu ihrer Expansion betrachtet, ein reaktionäres Ereignis der modernen chinesischen Geschichte. ${ }^{607}$
\end{abstract}

Indem er den Kampf gegen die Rechten als ein von Mao gelenktes „reaktionäres Ereignis“ charakterisiert, gelangt auch er zu einer kritischen Neudeutung der Kampagne. Auf Deng Xiaopings Verantwortung für die Umsetzung der Kampagne geht er nicht ein, jedoch sehr wohl auf seine zentrale Rolle für die Bewertung der Kampagne in der 1981er Resolution. Demnach habe auch die Resolution einzig und allein dem Zweck gedient, die Ein-Parteien-Diktatur aufrechtzuerhalten. Er setzt die Rolle Deng Xiaopings nach 1976 in eine direkte Linie zur Politik Maos und erklärt außerdem, weshalb die Autoritäten an dem von ihm geschaffenen Narrativ festhalten müssten:

Das politische Muster, das mit diesem Erfolg verbunden ist, ist das Vermächtnis, das Mao Zedong seinen politischen Nachfolgern in der Kommunistischen Partei Chinas hinterlassen hat. Dieses politische Muster hat auch eine negative Seite, die dazu geführt hat, dass es keiner mehr wagt, sich zu äußern; es hat auch eine positive Seite, die dazu genutzt werden kann, die „Harmonie“ aufrechtzuerhalten. Deshalb müssen die höchsten Autoritäten heute das reaktionäre Ereignis der Kampagne gegen Rechtsabweichler leugnen und dessen Richtigkeit bekräftigen. ${ }^{608}$

607 Eigene Übersetzung. Original siehe Gao 2012, S. 21.

608 Eigene Übersetzung. Original siehe ebd., S. 22. 
In dieser Hinsicht charakterisiert der Autor Deng Xiaoping im negativsten Sinne des Wortes als Nachfolger Mao Zedongs.

Yan Jiawei 严家伟 hingegen erwähnt zwar durchaus, dass Deng Xiaoping auch eine zentrale Rolle in der Kampagne gegen Rechtsabweichler innegehabt habe, jedoch schreibt auch er im Wesentlichen Mao die Hauptverantwortung zu:

Deng wollte die wirtschaftlichen Interessen in den Vordergrund rücken, um seine Position zu festigen, und deshalb musste er das ursprünglich „rechte“ Personal für deren effektive Umsetzung einsetzen. Dennoch hat Dengs Schritt noch immer eine progressive Bedeutung. Aber die Kampagne gegen Rechtsabweichler gehört zu den großen Sünden Maos und Dengs. Mao war der Oberbefehlshaber und Deng sein Stellvertreter. ${ }^{609}$

Allerdings kritisiert er, dass Deng Xiaoping seine eigene Schuld an der „großen Sünde“ der Kampagne gegen Rechtsabweichler niemals öffentlich eingeräumt habe. Auf die Details der Rolle Dengs während der Jahre 1957 und 1958 geht er jedoch nicht ein. Der Hauptpunkt der Kritik Yans an Deng betrifft dessen politisches Agieren nach dem Tode Maos. Er sieht ihn, ebenso wie Gao, als Verantwortlichen für die Bewertung der Kampagne in der 1981er Resolution. Er führt aus, dass diese nicht nur zu einer falschen Bewertung des Kampfes gegen die Rechten geführt habe, sondern dass durch die Resolution die Tragödie der Kampagne gegen Rechtsabweichler zu einer Farce verkommen sei.

Wie in dem Beitrag Yan Jiaweis wird die historische Rolle Deng Xiaopings auch in anderen Artikeln zwar stellenweise erwähnt, aber in keinem von ihnen wird sie detailliert erörtert. $\mathrm{Zu}$ berücksichtigen ist hier, dass die Rolle Dengs während der Kampagne gegen Rechtsabweichler auch in der westlichen Forschung nur unzureichend besprochen wird, was wiederum am mangelnden Zugang zu entsprechenden historischen Dokumenten liegen dürfte. Auch die Autoren der Zeitschrift Bashan Yeyu haben wahrscheinlich keinen Zugang zu entsprechenden Dokumenten oder zu Entscheidungsträgern der damaligen Zeit und damit zu weiterführenden Informationen. Deswegen liegt der Fokus der kritischen Betrachtungsweise Deng Xiaopings in den Artikeln weitgehend auf der offiziellen historischen Bewertung der Kampagne und dem Umgang mit den sogenannten Rechtsabweichlern nach 1978.

Was die historische Bewertung betrifft, sind sich die Autoren, die sich in ihren Artikeln diesem Aspekt der Geschichte zuwenden, weitgehend einig, dass die Art und Weise, wie die Kampagne gegen Rechtsabweichler in der 1981er Resolution besprochen worden ist, einzig und allein dem Machterhalt Deng Xiaopings gedient habe und er als wichtigster politischer Entscheidungsträger jener Jahre

609 Eigene Übersetzung. Original siehe Yan 2014, S. 25. 
deshalb kein Interesse an einer umfangreichen Aufarbeitung gehabt habe. Auch Lei Chonggong 雷崇功 legt dar, dass das von den politischen Erben geschaffene Narrativ nur dem Erhalt des politischen Systems diene:

Deng Xiaoping sagte, dass den „mörderischen“ Rechtsabweichlern im Jahr 1957 Unrecht geschehen ist. Die Rechten waren zu jener Zeit sehr bescheiden und vorsichtig, der Diktator, der im Besitz der Waffen war, war derjenige, der „mörderisch“ war, und tatsächlich „verhingen dunkle Wolken die Stadt, um sie zu überwältigen“. Tatsächlich wurde die Bewegung gegen die Rechten in den Köpfen der Menschen lange Zeit abgelehnt; die Theorie Deng Xiaopings und seiner Erben ist es nicht wert, widerlegt zu werden; sie befürchten selbst, dass sie nicht geglaubt wird, sie haben nur Angst, dass das Gesicht der Henker aufgedeckt wird. Können wir harmonisch und stabil sein, ohne die historischen Schulden zu begleichen und ohne das politische System zu reformieren? Ich befürchte, dass eine Situation geschaffen wurde, in der sich keiner mehr traut, etwas zu sagen und in der die Unzufriedenheit der Menschen wächst. ${ }^{610}$

Der Beitrag Leis stellt zudem ein weiteres Beispiel dafür dar, weshalb ein großer Teil dieser Artikel nicht von der Partei toleriert werden kann. Denn als er über das politische Schweigen über die wahren Vorgänge rund um die Kampagne gegen Rechtsabweichler spricht, stellt er einen direkten Zusammenhang zu anderen, teilweise noch stärker tabuisierten Themen her. Somit lenkt er die Aufmerksamkeit sowohl auf andere historische Ereignisse als auch auf Tabuthemen der aktuellen Politik wie die Verfolgung Falun-Gong-Praktizierender:

Es gibt sehr viele Tabus in der chinesischen Gesellschaft, es ist nicht nur die Kampagne gegen Rechtsabweichler, es ist auch das Tian'anmen-Massaker und das Blut Falun-GongPraktizierender, welches noch immer in die Herzen der Menschen im ganzen Land fließt, und es ist nicht gestattet, darüber zu sprechen - einige Menschen haben deswegen Schwierigkeiten, in ihr Land, nach Hause zurückzukehren. Sogar die tief liegenden Wurzeln der Kulturrevolution, die vollständig abgelehnt wird, lassen sich nicht erforschen. Rückblickend waren der Futian-Zwischenfall während der Zeit der Roten Armee, die Yan'an-Berichtigungsbewegung, die Landreform in den 1950er Jahren, die Kampagnen gegen Konterrevolutionäre, die ideologischen Umerziehungsmaßnahmen, die Hu-Feng-Kampagne, der Große Sprung nach vorn und unzählige andere politische Bewegungen alles sich wiederholende Fehler, für die sich die KPCh wiederholt nicht entschuldigt hat. ${ }^{611}$

Ebenso wie in der von der Partei tolerierten inoffiziellen Geschichtsschreibung kann auch hier die Art und Weise der Rehabilitierung bzw. der Einzelfallkorrekturen der Rechtsabweichler einen Einfluss auf die in dieser Kategorie geschaffenen Narrative ausüben. Die kritische Betrachtung dieser Vorgänge nach 1978 übt

610 Eigene Übersetzung. Original siehe Lei 2012, S. 19.

611 Eigene Übersetzung. Original siehe ebd., S. 19. 
gleichermaßen auch einen Einfluss auf die kritische Betrachtung des historischen Erbes Deng Xiaopings aus. Einige Autoren prangern an, dass die „Entschädigungszahlungen“ viel zu gering gewesen seien und nicht ansatzweise den Verdienstausfällen der jeweiligen Rechtsabweichler entsprochen hätten, und schon gar nicht hätten sie eine Wiedergutmachung des Leids der Opfer selbst oder auch das ihrer Familien dargestellt. Ein anonymer Autor vertritt die Ansicht, dass es sich hierbei schlicht um Betrug gehandelt habe. Er hält das Verhalten der Behörden für einen Skandal und wirft ihnen kriminelle Machenschaften vor:

Im Jahr 1978 setzte das Zentralkomitee der Kommunistischen Partei Chinas die Einzelfallkorrekturen der Rechtsabweichler um, welche nicht mehr nur keine Auszahlung der Löhne mehr umfassten, sondern auch nicht mehr die vom Staatsrat ursprünglich festgelegten „Unterhaltszahlungen“ und „Rücklagenfonds für Familien“ aufwies. Wo sind die 21 Jahre lang angesparten „Unterhaltszahlungen“ und „Rücklagefonds für Familien“ geblieben? Wurde es für Korruption aufgewendet? Liegt Betrug vor? Keiner sagt etwas. Wie konnte der Staatsrat einen solchen Skandal auslösen? ${ }^{612}$

Der Autor kritisiert in diesem Zusammenhang zudem, dass die Rückkehr in die Gesellschaft aus dem Laogai-System nur unzureichenden Regeln unterlegen habe und es deshalb beispielsweise vorgekommen sei, dass die ehemaligen Arbeitgeber sich geweigert hätten, den jeweiligen ehemaligen Rechtsabweichler wieder an seinem ursprünglichen Arbeitsplatz einzusetzen, was teilweise als demütigend empfunden worden sei. Der allgemeine Tenor der Artikel, die sich mit der Rückkehr der Rechtsabweichler in die Gesellschaft beschäftigen, lautet, dass die Art und Weise der Durchführung durch die Behörden ein Spiegelbild für die Verantwortungslosigkeit der KPCh darstelle. Die meisten von ihnen gehen mit einer Forderung nach einer angemessenen (posthumen) finanziellen Entschädigung einher. ${ }^{613}$

Die kritische Betrachtung der Vergangenheit steht, wie bereits die Auseinandersetzung mit den Einzelfallkorrekturen gezeigt hat, in Bashan Yeyu in der Regel nicht für sich, sondern sie geht in den meisten Artikeln mit konkreten Forderungen an die KPCh einher. Neben der Forderung nach einer angemessenen finanziellen Entschädigung der ehemaligen Rechtsabweichler und ihrer Familien umfassen sie konkrete Forderungen nach einer umfangreichen offiziellen Aufarbeitung der Geschichte, eine offizielle Entschuldigung der Partei oder der Errichtung von Gedenkstätten für die Opfer.

612 Eigene Übersetzung. Original siehe Anonym 2013b, S. 30.

613 Siehe zum Beispiel Li 2010. 
In einem Artikel gibt es zum Beispiel eine konkrete Forderung nach einer Gedenkstätte an dem Standpunkt des ehemaligen Umerziehungslagers Jiabiangou, wo daran erinnert werden soll, dass die Menschen dort an Demütigung, Arbeit und Hunger verstorben seien. ${ }^{614}$ Hinter Forderungen wie dieser steht nicht nur die Intention, einen Gedenkort für die Opfer zu schaffen, sondern sie steht stellvertretend für die häufig wiederholte Forderung an die gegenwärtige Regierung, die Fehler und Verbrechen der Kampagne gegen Rechtsabweichler durch die Partei umfassend zu reflektieren, um so $\mathrm{zu}$ einem gesellschaftlichen Fortschritt zu kommen. Die post-maoistische Erinnerungspolitik der KPCh wird immer wieder scharf und über die Grenzen des von der Partei Tolerierbaren hinausgehend angegriffen, indem ihr etwa im Umgang mit der Geschichte Verantwortungslosigkeit vorgeworfen wird. Demnach müsse sie zu einer umfassenden Reflexion bereit sein, sodass zukünftige Generationen aus den Fehlern der Vergangenheit lernen und die Partei somit ihrer gesellschaftlichen Verantwortung nachkommt:

Der Zweck der Aufzeichnung dieser Zahlen besteht darin, die Menschen und zukünftige Generationen an die schmerzhafte Geschichte der Kampagne gegen Rechtsabweichler zu erinnern, sie von ihr und der Geschichte lernen zu lassen, sodass sich eine solche historische Tragödie nicht wiederholt und das Land keine Umwege macht und die Menschen nicht leiden lässt. Eine Nation, die ernsthaft über die Geschichte nachdenken kann, ist eine vielversprechende Nation: Eine Regierung, die mit der Verleumdung richtig umgehen kann, ist eine verantwortungsvolle Regierung. ${ }^{615}$

Diese Beiträge lassen sich also auch als ein Versuch der politischen Partizipation deuten. Stellvertretend für viele seiner Schicksalsgenossen fasst Lei Chonggong wesentliche Punkte zusammen, die die inhaltlichen Grundlagen des Aktes der politischen Partizipation durch die Opfer der Kampagne gegen Rechtsabweichler darstellen, denn, so schreibt er, er und seine Weggefährten würden nicht eher ruhen, bis die folgenden Punkte erreicht seien:

1. Ich hoffe, dass ich ein objektives Urteil über mein Leben werde ziehen können und die Freigabe meiner Rechtsabweichler-Akte fordern kann. 2. Die Rechtsabweichler sind unnachgiebig und streben nach vollständiger Wiedergutmachung sowie ihrem Recht, ihre Ansprüche geltend machen zu können, nach einer Rückzahlung der Schulden, nach Gerechtigkeit und sie fordern die Kommunistische Partei dazu auf, ihre Fehler öffentlich zuzugeben und sich entsprechend zu entschuldigen und Entschädigungen zu leisten. 3. Sie bemühen sich, ein Museum zur Kulturrevolution und zur Kampagne gegen Rechtsabweichler zu errichten, Materialien zu sammeln, Memoiren zu schreiben und Artikel zu diskutieren,

614 Anonym 2013a, S. 8.

615 Eigene Übersetzung. Original siehe Yan 2013, S. 5. 
sich auszutauschen und zu koordinieren sowie ihr Recht auf Versammlungsfreiheit auszuüben. 4. Die Rechtsabweichler, die überlebt haben, sollen ein gesundes und langes Leben, Zeit und Energie haben, um zu beobachten, was die Behörden als nächstes planen, und sich Schritte überlegen können, was als nächstes zu tun ist; sie glauben daran, dass die Geschichte ein fairer Richter ist. ${ }^{616}$

Das Sprechen über die schmerzhafte Vergangenheit wird in einigen Artikeln in Bashan Yeyu auch in Verbindung mit einer Kritik an aktuellen politischen Entwicklungen gebracht. Die Autoren kommentieren kritisch das, was ihnen an der gegenwärtigen Politik missfällt, und argumentieren dabei mit dem Negativbeispiel der Kampagne gegen Rechtsabweichler. Huang Baosong 煌宝松 kommentiert in dieser Weise die politischen Entwicklungen seit der Amtsübernahme Xi Jinpings und insbesondere die Idee des Chinesischen Traums, welcher nach Meinung des Autors ohne die tatsächliche Anwendung der chinesischen Verfassung nicht verwirklicht werden könne:

In anderen Worten ist der „Chinesische Traum“ das Ziel des „konstitutionellen Traums“ und der „konstitutionelle Traum“ stellt die Garantie für den „Chinesischen Traum“ dar. Wenn man nun zulässt, dass der „Chinesische Traum“ kein „konstitutioneller Traum“ ist, ist das ebenso dumm und unangebracht, wie wenn man auf einem Bein und einem Fuß geht. ${ }^{617}$

Die Verknüpfung mit der Kampagne gegen Rechtsabweichler stellt der Autor insofern her, als dass er argumentiert, dass sich die Machthaber in jenen Jahren gegen die Verfassung gewandt hätten und die gegenwärtige politische Führung dies ebenfalls tue. Auch hier spielt das individuelle Gedächtnis wieder eine große Rolle, da er hier von seinen eigenen Erlebnissen als $\mathrm{zu}$ Unrecht verurteilter Rechtsabweichler berichtet, was er ganz klar als einen Verstoß gegen die Verfassung ansieht. Dementsprechend müsse die chinesische Regierung aus den Fehlern der Kampagne gegen Rechtsabweichler lernen und zukünftig die Verfassung der VR China tatsächlich auch umsetzen. Dabei erwähnt er, dass dies eigentlich sogar einer Rede von Xi Jinping entspreche, die er im Dezember 2012 anlässlich des 30-jährigen Jubiläums der Verfassung gehalten hat und in der er sich für die Verteidigung der Würde der Verfassung aussprach. In diesem Zusammenhang betonte Xi auch, dass man die Rechte und Freiheiten des Volkes schwächen würde, wenn man die Verfassung missachte. In der Rede deutete er zudem an, dass dieser Fehler in der Vergangenheit, insbesondere während der Kulturrevolution, durchaus gemacht worden sei und deshalb wies er darauf hin:

616 Eigene Übersetzung. Original siehe Lei 2012, S. $19 \mathrm{f}$.

617 Eigene Übersetzung. Original siehe Huang 2013, S. 43. 
„Aus der Geschichte kann man immer lernen. “618 Huang betont in diesem Zusammenhang, dass es an eben jenen von Xi Jinping angesprochenen Punkten auch im gegenwärtigen China noch mangele:

Man muss aus den Erfahrungen der Vergangenheit lernen, der Spiegel der Geschichte kann klar und reichhaltig sein, durch ihn kann man menschliche Gewinne und Verluste erkennen und so kann der Bronzespiegel wirklich eine Krone sein. Deshalb muss der „konstitutionelle Traum“ fortbestehen. Die Verfassung ist das Grundgesetz der Nation, die Grundlage der nationalen Regierung und die Strategie einer starken Nation und keine Organisation oder Einzelperson hat die Macht, sich über die Verfassung zu stellen, doch wenn sich jeder der in der Verfassung verankerten Rechte und Pflichten annimmt, wieso gedeiht das Land nicht und wieso lebt das Volk nicht in Glück und Würde? Deshalb sollten das Festhalten an der Verfassung, die Verfassungsmäßigkeit und die Konstitutionalisierung der Konsens aller Menschen sein. Dennoch liegt die Autorität der Verfassung in ihrer Umsetzung, aber sie enthält viele Klauseln, die ihre vollständige Umsetzung verhindert. ${ }^{619}$

Konkret geht er dabei auf die mangelnde Umsetzung des Artikels 35 der aktuellen Verfassung ein. Dieser lautet: „Die Bürger der Volksrepublik China genießen die Freiheit der Rede, der Publikation, der Versammlung, der Vereinigung, der Durchführung von Straßenumzügen und Demonstrationen."620 Er zieht eine Parallele zur Kampagne gegen Rechtsabweichler, indem er sowohl den Machthaben der 1950er Jahre Verfassungsbruch ${ }^{621}$ vorwirft als auch der gegenwärtigen Regierung. Bezüglich der mangelnden Umsetzung des Artikels 35 greift er die KPCh direkt an und agiert damit deutlich jenseits der Grenzen des Sagbaren, indem er sich auf tabuisierte Ereignisse bezieht, in denen der Staat seiner Meinung nach Verfassungsbruch begangen habe. So prangert er die, seiner Meinung nach, illegale Inhaftierung des blinden Menschenrechtsaktivisten Chen Guangcheng 陈光诚 ${ }^{622}$ während der Präsidentschaft $\mathrm{Hu}$ Jintaos sowie die menschenunwürdige Behandlung des seit 2008 in Haft befindlichen Menschenrechtlers Liu Xiaobos 刘晓波 an. Dieser Artikel dient somit als ein weiteres Beispiel für viele weitere Artikel in Bashan Yeyu, in denen der Autor jeweils darüber spricht, worüber eigentlich nicht öffentlich gesprochen werden soll bzw. darf.

618 Siehe Rede zum 30-jährigen Jubiläum der geltenden Verfassung. Xi 2014, S. 165.

619 Eigene Übersetzung. Original siehe Huang 2013, S. 44.

620 Verfassung der Volksrepublik China vom 04. Dezember 1982, Artikel 35.

621 Artikel 87 der 1954er Verfassung formulierte die gleichen Rechte wie Artikel 35 der gegenwärtigen Verfassung.

622 Für weitere Informationen zu den Hintergründen der Verhaftung Chens siehe Siemons 2012, https://www.faz.net/aktuell/feuilleton/chen-guangcheng-der-blinde-der-china-die-augen-oeff net-11738583.html. 
Zusammenfassend lässt sich sagen, dass, wenn die Autoren in ihren Artikeln zu einer Kritik an der Partei ansetzen, diese noch deutlich schärfer ausfällt, als in den Artikeln der bis Juni 2016 staatlich tolerierten Geschichtszeitschrift Yanhuang Chunqiu. In Bashan Yeyu werden dabei auch konkrete Zahlen genannt und im Zuge dessen wird die KPCh teilweise auch offen der Lüge bezichtigt. Auch wenn andere Artikel dieser Zeitschrift, insbesondere die Kurzmemoiren, denen in staatlich tolerierten Veröffentlichungen ähneln, wird schnell deutlich, warum Bashan Yeyu keine staatliche Tolerierung zukommen konnte. Dies gilt umso mehr seit der Amtsübernahme Xi Jinpings. Insgesamt stellen die Inhalte der Zeitschrift in ihrer Art der Darstellung der Kampagne gegen Rechtsabweichler die Herrschaftslegitimation der KPCh zu deutlich in Frage. 